\title{
Extended VIKOR Method for Intuitionistic Fuzzy Multiattribute Decision-Making Based on a New Distance Measure
}

\author{
Xiao Luo ${ }^{1}$ and Xuanzi Wang ${ }^{2}$ \\ ${ }^{1}$ School of Air and Missile Defense, Air Force Engineering University, Xi'an 710051, China \\ ${ }^{2}$ School of Management, Xian Jiaotong University, Xian 710049, China \\ Correspondence should be addressed to Xiao Luo; xiao_hngz@163.com
}

Received 24 June 2017; Revised 18 September 2017; Accepted 27 September 2017; Published 29 October 2017

Academic Editor: Anna M. Gil-Lafuente

Copyright ( 2017 Xiao Luo and Xuanzi Wang. This is an open access article distributed under the Creative Commons Attribution License, which permits unrestricted use, distribution, and reproduction in any medium, provided the original work is properly cited.

An intuitionistic fuzzy VIKOR (IF-VIKOR) method is proposed based on a new distance measure considering the waver of intuitionistic fuzzy information. The method aggregates all individual decision-makers' assessment information based on intuitionistic fuzzy weighted averaging operator (IFWA), determines the weights of decision-makers and attributes objectively using intuitionistic fuzzy entropy, calculates the group utility and individual regret by the new distance measure, and then reaches a compromise solution. It can be effectively applied to multiattribute decision-making (MADM) problems where the weights of decision-makers and attributes are completely unknown and the attribute values are intuitionistic fuzzy numbers (IFNs). The validity and stability of this method are verified by example analysis and sensitivity analysis, and its superiority is illustrated by the comparison with the existing method.

\section{Introduction}

Multiattribute decision-making (MADM), which has been increasingly studied and is of concern to researchers and administrators, is one of the most important parts of decision theory. It aims to provide a comprehensive solution by evaluating and ranking alternatives based on conflicting attributes with respect to decision-makers' (DMs') preferences and has widely been used in engineering, economics, and management. Several classical MADM methods have been proposed by researchers in literature, such as the TOPSIS (Technique for Order Preference by Similarity to Ideal Solution) method [1], the VIKOR (VIseKriterijumska Optimizacija I Kompromisno Resenje in Serbian, meaning multiattribute optimization and compromise solution) method [2], the PROMETHEE (Preference Ranking Organization Method for Enrichment Evaluations) method [3], and the ELECTRE (Elimination and Choice Translating reality) method [4]. Among these methods, VIKOR is shown to have some advantages over others by several researchers. In [5], Opricovic and Tzeng compared VIKOR method and TOPSIS method from the perspective of aggregation function and found that although both methods calculate the distance of an alternative to the ideal solution, the former method provides a compromise solution by mutual concessions, while the latter method obtains a solution with the farthest distance from the negative-ideal solution and the shortest distance from the positive ideal solution without considering the relative importance degrees of these distances. Furthermore, Opricovic and Tzeng compared an extension of the VIKOR method comprehensively with the TOPSIS, ELECTRE, and PROMETHEE method and revealed that the VIKOR method is superior in meeting conflicting and noncommensurable attributes [6]. At present, the VIKOR method has wide application in many areas, such as design, mechanical engineering, and manufacturing [7-9], logistics and supply chain management $[10,11]$, structural, construction, and transportation engineering $[12,13]$, and business management [14].

Since Zadah put forward the concept of fuzzy sets in 1965, fuzzy sets, especially fuzzy numbers (e.g., triangular fuzzy numbers and trapezoidal fuzzy numbers), have been widely researched and applied in MADM problems to deal 
with uncertainty in actual decision-making process. Sayadi et al. extended the concept of VIKOR method to solve MADM problems with interval fuzzy numbers [15]. Kaya and Kahrarnan developed an integrated VIKOR-AHP method based on triangular fuzzy numbers in forestation district selection scenario [16]. Ashtiani and Abdollahi Azgomi constructed a trust modeling based on a combination of fuzzy analytic hierarchy process and VIKOR method with triangular fuzzy numbers [17]. Liu et al. applied the VIKOR method to find a compromise priority ranking of failure modes according to the risk factors, in which the weights of attributes and ratings of alternatives are linguistic variables represented by trapezoidal or triangular fuzzy numbers [18]. Ju and Wang proposed a new method to solve multiattribute group decision-making (MAGDM) problems based on the traditional idea of VIKOR method with trapezoidal fuzzy numbers [19]. However, none of the above-mentioned studies considered hesitancy. Due to the increasing complexity and uncertainty of economic environment, decision-makers' perception of things involves not only affirmation and negation, but also hesitation. Therefore, hesitation, as one of the most important pieces of uncertain information, may have great impact on the final decision and should be considered in decision-making process. To deal with this, Atanassov extended traditional fuzzy sets to intuitionistic fuzzy sets (IFSs) which consider membership, nonmembership, and degree of hesitancy at the same time. In practical application, the use of IFSs can depict the fuzziness and nonspecificity of problems by employing both membership function and nonmembership function. Therefore, it is considered to be more effective than classical FSs with merely a membership function. Recently, intuitionistic fuzzy VIKOR (IFVIKOR) method becomes a popular research topic because it aims to deal with the widespread uncertainty in decisionmaking process, and some researchers focus on the IFVIKOR method to solve MADM problems. For instance, Devi [20] first extended VIKOR method in intuitionistic fuzzy environment to deal with robot selection problem, in which the weights of attributes and ratings of alternatives are represented by triangular intuitionistic fuzzy sets (TIFSs). Lu and Tang [21] employed the VIKOR method to evaluate auto parts supplier based on IFSs. Roostaee et al. extended VIKOR method for group decision-making to solve the supplier selection problem under intuitionistic fuzzy environment [22]. Wan et al. put forward a new VIKOR method for MADM problem with TIFSs [23], in which the weights of attributes and DMs are completely unknown. Park et al. extended VIKOR method for dynamic intuitionistic fuzzy MADM concerning university faculty evaluation problem [24]. Based on similarity measure between IFSs, Peng et al. proposed a novel IF-VIKOR method to deal with multiresponse optimization problem, in which the importance of each response is given by an engineer as IFSs [25]. Hashemi et al. proposed a new compromise method based on classical VIKOR model with interval-valued intuitionistic fuzzy sets (IVIFSs), illustrated by an application in reservoir flood control operation [26]. Mousavi et al. presented a new group decision-making method for MADM problems based on IFVIKOR, in which the ratings of alternatives concerning each attribute and the weights of criterions provided by DMs are represented as linguistic variables, characterized by IFSs with multijudge [27].

Distance is an important fundamental concept of IFSs and plays a significant role in VIKOR method. The classical compromise programing is based on the distance measure which is determined by the closeness of a specific solution to the ideal/infeasible solution, maximizing the group utility and minimizing the individual regret simultaneously $[28,29]$. Although some existing methods employ intuitionistic fuzzy subtraction and division operator to calculate "group utility" and "individual regret," the result is in IFSs form and needs to be further sorted according to IFSs' ranking rule. To some extent, the amount of computation is increased, and the results are not concise as the crisp value obtained by distance measure. Also, some researchers [30-32] reviewed existing distance and similarity measures between IFSs and tested them with an artificial benchmark. The result showed that many existing distance measures generate counterintuitive cases and fail to capture waver, the lack of knowledge, which should have been an advantage of IFSs. On the one hand, existing distance measures are shown to have some limitations with hindered effectiveness, while, on the other hand, the measure choice is crucial to IF-VIKOR method due to its significant influence on the result. Therefore, this paper's objective is to construct a new distance measure, which can capture IFS information effectively. Based on this, an IF-VIKOR method is further proposed to solve MADM problems with completely unknown weights of DMs and attributes. The main features and novelties of this paper are as follows:

(1) Different from the VIKOR method based on classical fuzzy sets, such as interval fuzzy numbers [15], triangular fuzzy numbers [16-18], and trapezoidal fuzzy numbers [18, 19], the method proposed in this paper is based on IFSs, which adds a nonmembership on the basis of the traditional membership and is able to describe support, opposition, and neutrality in human cognition. Such an extended definition helps more adequately to represent situations when decision maker abstains or hesitates from expressing their assessments.

(2) Compared with the method [20, 27] employing intuitionistic fuzzy operator to calculate "group utility" and "individual regret," our method generates crisp value result in a more intuitive way with less computation. Although Roostaee et al. [22] extended the VIKOR method to intuitionistic fuzzy environment based on hamming distance, the method sometimes generates counterintuitive cases and takes no consideration of waver in IFSs. Instead, our method based on a new distance measure could reflect intuitionistic fuzzy information effectively. Also, the new distance does not generate counterintuitive cases in the artificial benchmark test proposed by [30].

(3) Compared with the VIKOR method $[20,23,26]$ based on those extensions of IFSs, IFSs possess sound theoretical foundation such as basic definition and operations, comparison rules, information fusion method, and measures of IFS. 
The proposed IF-VIKOR method can take advantage of these theories in construction and verification, which is favorable to practical application.

(4) Although IFSs have the advantage of being able to consider waver, most of existing IF-VIKOR methods are applied to environment with less nonspecificity information $[27,33]$. Through an example of ERP system selection, our paper illustrates the effectiveness of proposed method in such situation. Moreover, an example of material handling selection indicates that our method can obtain desired ranking result, superior in environment with low specificity.

(5) In the MADM problem with intuitionistic fuzzy numbers (IFNs), subjective randomness exists because the weights of DMs or attributes are usually given artificially $[22,27]$. To avoid this issue, these weights are determined objectively using intuitionistic fuzzy entropy in the proposed method.

(6) Compared with similar methods used for MADM [1, $3,4]$, the proposed method based on the decision principle of the classical VIKOR method can maximize the group utility and minimize the individual regret simultaneously, making the decision result more reasonable. Also, the coefficient of decision mechanism can be changed according to actual requirements to balance group utility and individual regret, which can increase the flexibility of decision-making.

The remainder of this paper is organized as follows. Section 2 reviews some basic concepts of IFSs. In Section 3, a new distance measure for IFSs is proposed and a comparative analysis is conducted. In Section 4, a new distance based IFVIKOR method is developed to deal with MADM problem. In Section 5, two application examples are demonstrated to highlight the applicability and superiority of proposed IFVIKOR method. The final section summarizes the main work of this paper with a discussion of implications for future research.

\section{Preliminaries}

In this section, we briefly review some basic notions and theories related to IFSs.

\subsection{Intuitionistic Fuzzy Set}

Definition 1. An intuitionistic fuzzy set $A$ in the universe of discourse $X$ is defined as follows [34]:

$$
A=\left\{\left\langle x, u_{A}(x), v_{A}(x)\right\rangle \mid x \in X\right\},
$$

where $u_{A}: X \rightarrow[0,1]$ and $v_{A}: X \rightarrow[0,1]$ are called membership function and nonmembership function of $x$ to $A$, respectively. $u_{A}(x)$ represents the lowest bound of degree of membership derived from proofs of supporting $x$ while $v_{A}(x)$ represents the lowest bound of degree of nonmembership derived from proofs of opposing $x$. For any $x \in X, 0 \leq u_{A}+v_{A} \leq 1$. The function $\pi_{A}(x)=1-u_{A}(x)-v_{A}(x)$ is called hesitance index, and $\pi_{A}(x) \in[0,1]$ represents the degree of hesitancy of $x$ to $A$. Specially, if $\pi_{A}(x)=0$, where $x \in X$ is known absolutely, the intuitionistic fuzzy set $A$ degenerates into a fuzzy set.
Definition 2. For convenience of computation, let $\widetilde{a}=\left(u_{a}, v_{a}\right)$ be an intuitionistic fuzzy number (IFN). Then the score function of $\widetilde{a}$ is defined as follows [35]:

$$
s(\widetilde{a})=\left(u_{a}-v_{a}\right) .
$$

And the accuracy function of $\tilde{a}$ is defined as follows [36]:

$$
h(\widetilde{a})=\left(u_{a}+v_{a}\right) .
$$

Let $\widetilde{a}_{1}$ and $\widetilde{a}_{2}$ be two IFNs; then Xu and Yager [37] proposed the following rules for ranking of IFNs:

(1) $s\left(\tilde{a}_{1}\right)<s\left(\tilde{a}_{2}\right)$, then $\tilde{a}_{1}$ is smaller than $\tilde{a}_{2}$, denoted by $\tilde{a}_{1}<\tilde{a}_{2}$

(2) $s\left(\tilde{a}_{1}\right)>s\left(\tilde{a}_{2}\right)$, then $\tilde{a}_{2}$ is smaller than $\tilde{a}_{1}$, denoted by $\tilde{a}_{1}>\tilde{a}_{2}$

(3) $s\left(\widetilde{a}_{1}\right)=s\left(\widetilde{a}_{2}\right)$, then

(i) $h\left(\widetilde{a}_{1}\right)=h\left(\widetilde{a}_{2}\right)$, then $\tilde{a}_{1}$ is equal to $\tilde{a}_{2}$, denoted by $\tilde{a}_{1}=\tilde{a}_{2}$

(ii) $h\left(\widetilde{a}_{1}\right)<h\left(\widetilde{a}_{2}\right)$, then $\tilde{a}_{1}$ is smaller than $\tilde{a}_{2}$, denoted by $\tilde{a}_{1}<\tilde{a}_{2}$;

(iii) $h\left(\widetilde{a}_{1}\right)>h\left(\widetilde{a}_{2}\right)$, then $\tilde{a}_{2}$ is smaller than $\tilde{a}_{1}$, denoted by $\widetilde{a}_{1}>\widetilde{a}_{2}$.

Definition 3. Let $\tilde{a}_{i}(i=1,2, \ldots, n)$ be the set of IFNs, where $\tilde{a}_{i}=\left(u_{\tilde{a}_{i}}, v_{\tilde{a}_{i}}\right)$. The intuitionistic fuzzy weighted averaging (IFWA) operator can be defined as follows [33]:

$$
\begin{aligned}
& \operatorname{IFWA}_{w}\left(\widetilde{a}_{1}, \widetilde{a}_{2}, \ldots, \widetilde{a}_{n}\right)=w_{1} \widetilde{a}_{1} \oplus w_{2} \widetilde{a}_{2} \oplus \cdots \oplus w_{n} \widetilde{a}_{n} \\
& =\left(1-\prod_{i=1}^{n}\left(1-u_{\widetilde{a}_{i}}\right)^{w_{i}}, \prod_{i=1}^{n} v_{\widetilde{a}_{i}} w_{i}\right)
\end{aligned}
$$

where $w_{i}$ is the weight of $\widetilde{a}_{i}(i=1,2, \ldots, n), w_{i} \in[0,1]$, and $\sum_{i=1}^{n} w_{i}=1$.

Definition 4. Let $A$ be an intuitionistic fuzzy set in the universe of discourse $X$. Intuitionistic fuzzy entropy is given as follows [38]:

$$
E(A)=\frac{1}{n} \sum_{i=1}^{n} \frac{\min \left(u_{A}\left(x_{i}\right), v_{A}(x)\right)+\pi_{A}(x)}{\max \left(u_{A}\left(x_{i}\right), v_{A}(x)\right)+\pi_{A}(x)}
$$

\subsection{Distance Measure between IFSs}

Definition 5. For any $A, B, C \in \operatorname{IFS} s(X)$, let $d$ be a mapping $d$ : $\operatorname{IFSs}(X) \times \operatorname{IFSs}(X) \rightarrow[0,1]$. If $d(A, B)$ satisfies the following properties [39]:

(DP1) $0 \leq d(A, B) \leq 1$;

(DP2) $d(A, B)=0$ if and only if $A=B$;

(DP3) $d(A, B)=d(B, A)$; 
(DP4) if $A \subseteq B \subseteq C$, then $d(B, C) \leq d(A, C)$ and $d(A, B) \leq$ $d(A, C)$,

then $d(A, B)$ is a distance measure between IFSs $A$ and $B$.

Let $X$ be the universe of discourse, where $X=\left\{x_{1}, x_{2}\right.$, $\left.\ldots, x_{n}\right\}$, and let $A$ and $B$ be two IFSs in the universe of discourse $X$, where $A=\left\{\left\langle x_{i}, u_{A}\left(x_{i}\right), v_{A}\left(x_{i}\right)\right\rangle \mid x_{i} \in X\right\}$ and $B=\left\{\left\langle x_{i}, u_{B}\left(x_{i}\right), v_{B}\left(x_{i}\right)\right\rangle \mid x_{i} \in X\right\}$. Several widely used distance measures are reviewed as follows.

In [40], Szmidt and Kacprzyk proposed four distances between IFSs using the well-known hamming distance, Euclidean distance, and their normalized counterparts as follows:

$$
\begin{aligned}
d_{H}(A, B) & =\frac{1}{2} \sum_{i=1}^{n}\left[\left|u_{A}\left(x_{i}\right)-u_{B}\left(x_{i}\right)\right|+\left|v_{A}\left(x_{i}\right)-v_{B}\left(x_{i}\right)\right|+\left|\pi_{A}\left(x_{i}\right)-\pi_{B}\left(x_{i}\right)\right|\right], \\
d_{n H}(A, B) & =\frac{1}{2 n} \sum_{i=1}^{n}\left[\left|u_{A}\left(x_{i}\right)-u_{B}\left(x_{i}\right)\right|+\left|v_{A}\left(x_{i}\right)-v_{B}\left(x_{i}\right)\right|+\left|\pi_{A}\left(x_{i}\right)-\pi_{B}\left(x_{i}\right)\right|\right], \\
d_{E}(A, B) & =\sqrt{\frac{1}{2} \sum_{i=1}^{n}\left[\left(u_{A}\left(x_{i}\right)-u_{B}\left(x_{i}\right)\right)^{2}+\left(v_{A}\left(x_{i}\right)-v_{B}\left(x_{i}\right)\right)^{2}+\left(\pi_{A}\left(x_{i}\right)-\pi_{B}\left(x_{i}\right)\right)^{2}\right]} \\
d_{n E}(A, B) & =\sqrt{\frac{1}{2 n} \sum_{i=1}^{n}\left[\left(u_{A}\left(x_{i}\right)-u_{B}\left(x_{i}\right)\right)^{2}+\left(v_{A}\left(x_{i}\right)-v_{B}\left(x_{i}\right)\right)^{2}+\left(\pi_{A}\left(x_{i}\right)-\pi_{B}\left(x_{i}\right)\right)^{2}\right] .}
\end{aligned}
$$

Wang and Xin [39] pointed out that Szmidt and Kacprzyk's distance measures [40] have some good geometric properties, but there are some limitations in the application. Therefore, they proposed several new distances as follows.

$$
\begin{aligned}
& d_{1}(A, B)=\frac{1}{n} \\
& \cdot \sum_{i=1}^{n}\left[\frac{\left|u_{A}\left(x_{i}\right)-u_{B}\left(x_{i}\right)\right|+\left|v_{A}\left(x_{i}\right)-v_{B}\left(x_{i}\right)\right|}{4}\right. \\
& \left.+\frac{\max \left(\left|u_{A}\left(x_{i}\right)-u_{B}\left(x_{i}\right)\right|,\left|v_{A}\left(x_{i}\right)-v_{B}\left(x_{i}\right)\right|\right)}{2}\right], \\
& d_{2}^{P}(A, B)=\frac{1}{\sqrt[p]{n}} \\
& \cdot \sqrt[p]{\sum_{i=1}^{n}\left(\frac{\left|u_{A}\left(x_{i}\right)-u_{B}\left(x_{i}\right)\right|+\left|v_{A}\left(x_{i}\right)-v_{B}\left(x_{i}\right)\right|}{2}\right)^{p}} .
\end{aligned}
$$

On the basis of the Hausdorff metric, Grzegorzewski [41] put forward some approaches for computing distances between IFSs, and these suggested distances are also generalizations of the well-known hamming distance, Euclidean distance, and their normalized counterparts.

$$
\begin{aligned}
& d_{h}(A, B) \\
& =\sum_{i=1}^{n} \max \left\{\left|u_{A}\left(x_{i}\right)-u_{B}\left(x_{i}\right)\right|,\left|v_{A}\left(x_{i}\right)-v_{B}\left(x_{i}\right)\right|\right\}, \\
& l_{h}(A, B) \\
& =\frac{1}{n} \sum_{i=1}^{n} \max \left\{\left|u_{A}\left(x_{i}\right)-u_{B}\left(x_{i}\right)\right|,\left|v_{A}\left(x_{i}\right)-v_{B}\left(x_{i}\right)\right|\right\}, \\
& e_{h}(A, B) \\
& =\sqrt{\sum_{i=1}^{n} \max \left\{\left(u_{A}\left(x_{i}\right)-u_{B}\left(x_{i}\right)\right)^{2},\left(v_{A}\left(x_{i}\right)-v_{B}\left(x_{i}\right)\right)^{2}\right\},} \\
& q_{h}(A, B) \\
& =\sqrt{\frac{1}{n} \sum_{i=1}^{n} \max \left\{\left(u_{A}\left(x_{i}\right)-u_{B}\left(x_{i}\right)\right)^{2},\left(v_{A}\left(x_{i}\right)-v_{B}\left(x_{i}\right)\right)^{2}\right\} .}
\end{aligned}
$$

Yang and Chiclana [42] suggested that the 3D interpretation of IFSs could provide different contradistinction results to the ones obtained with their $2 \mathrm{D}$ counterparts [41] and introduced several extended 3D Hausdorff based distances.

$$
\begin{aligned}
d_{e h}(A, B) & =\sum_{i=1}^{n} \max \left\{\left|u_{A}\left(x_{i}\right)-u_{B}\left(x_{i}\right)\right|,\left|v_{A}\left(x_{i}\right)-v_{B}\left(x_{i}\right)\right|,\left|\pi_{A}\left(x_{i}\right)-\pi_{B}\left(x_{i}\right)\right|\right\}, \\
l_{e h}(A, B) & =\frac{1}{n} \sum_{i=1}^{n} \max \left\{\left|u_{A}\left(x_{i}\right)-u_{B}\left(x_{i}\right)\right|,\left|v_{A}\left(x_{i}\right)-v_{B}\left(x_{i}\right)\right|,\left|\pi_{A}\left(x_{i}\right)-\pi_{B}\left(x_{i}\right)\right|\right\},
\end{aligned}
$$




$$
\begin{aligned}
& e_{e h}(A, B)=\sqrt{\sum_{i=1}^{n} \max \left\{\left(u_{A}\left(x_{i}\right)-u_{B}\left(x_{i}\right)\right)^{2},\left(v_{A}\left(x_{i}\right)-v_{B}\left(x_{i}\right)\right)^{2},\left(\pi_{A}\left(x_{i}\right)-\pi_{B}\left(x_{i}\right)\right)^{2}\right\}}, \\
& q_{e h}(A, B)=\sqrt{\frac{1}{n} \sum_{i=1}^{n} \max \left\{\left(u_{A}\left(x_{i}\right)-u_{B}\left(x_{i}\right)\right)^{2},\left(v_{A}\left(x_{i}\right)-v_{B}\left(x_{i}\right)\right)^{2},\left(\pi_{A}\left(x_{i}\right)-\pi_{B}\left(x_{i}\right)\right)^{2}\right\}} .
\end{aligned}
$$

\section{New Distance Measure between IFSs}

3.1. Analysis on Existing Distance Measures between IFSs Although various types of distance measures between IFSs were proposed over the past several years and most of them satisfies the distance axioms (Definition 5), some unreasonable cases can still be found [31, 32]. For example, consider three single-element IFSs $A=(x, 0.4,0.2), B=(x, 0.5,0.3)$, and $C=(x, 0.5,0.2)$. In this case, the distance between $A$ and $B$ calculated by some existing measures (e.g., $d_{n H}, d_{n E}, l_{h}, l_{e h}$, $\left.d_{1}, d_{2}^{P}\right)$ is equal to or greater than that between $A$ and $C$, which does not seem to be reasonable since IFSs $A, B$, and $C$ are ordered as $C>B>A$ according to the score function and accuracy function given in Definition 2, indicating that the distance between $A$ and $B$ is smaller than that between $A$ and $C$. For one reason, different distance measures have different focus, which may be suitable for different applications. For another, this could mean the definition of distance measures is too weak. Specifically, the definition may be more complete and reasonable if it has considered the following two aspects. First, Definition 5 just provides the value constraints when $d(A, B)=0$, and the other endpoint $d(A, B)=1$ has not been discussed. Second, the distance measure between IFSs could be better convinced if it satisfies the requirement of the triangle inequality.

Another point worth noting is that there are two facets of uncertainty of intuitionistic fuzzy information, one of which is related to fuzziness while the other is related to lack of knowledge or nonspecificity [43]. First, IFSs are an extension of FSs and hence are associated with fuzziness. This fuzziness is the first kind of uncertainty that mainly reflects two types of distinct and specific information: degree of membership and degree of nonmembership. In IFSs there exists another kind of uncertainty that can be called lack of knowledge or nonspecificity and might also be called waver [30]. This kind of uncertainty reflects a type of nonspecific information: degree of hesitancy, indicating how much we do not know about membership and nonmembership. These two kinds of uncertainty are obviously different, the degree of hesitancy with its own uncertainty because it represents a state of "both this and that." However, most of the existing distance measures only consider the differences between numerical values of the IFS parameters and ignore the waver of intuitionistic fuzzy information. As an illustration, consider two patterns represented by IFSs $A=(x, 0.1,0.2)$ and $B=(x, 0.1,0.2)$, in which both hesitance indexes of $A$ and $B$ are equal to 0.7. In this case, the distance between IFSs $A$ and $B$ calculated by all aforementioned measures is equal to zero, denoting that the two patterns are the same. This is true from the perspective of numerical value because the three parameters of IFSs $A$ and $B$ have the same value. However, from the perspective of intuitionistic fuzzy information, the conclusion drawn is unreasonable. The hesitance index $\pi(x)=1-u(x)-v(x)$ in both IFSs $A$ and $B$ is equal to 0.7 , but it just means that in IFSs $A$ and $B$ the proportion of lack of knowledge is 0.7 , and it cannot represent that the patterns $A$ and $B$ are the same. In other words, since we have a lack of knowledge, we should not draw the conclusion that the two patterns are the same.

As a powerful tool in modeling uncertain information, IFSs have the advantage of being able to consider waver mainly because the hesitant index can be used to describe a neutrality state of "both this and that." Moreover, it should be noted that the ultimate goal of distance measure is to measure the difference of information carried by IFSs, rather than the numerical value of IFSs themselves. Therefore, in our view the distance measure should take into account the characteristics of intuitionistic fuzzy information, both fuzziness and nonspecificity, and have its own target.

3.2. Intuitive Distance for IFSs. Inspired by the characteristics of intuitionistic fuzzy information, we introduce a notion called intuitive distance to compare the information between two IFSs and compute the degree of difference, and the axiomatic definition of intuitive distance is as follows.

Definition 6. For any $A, B, C, D \in \operatorname{IFSs}(X)$, let $d$ be a mapping $d: \operatorname{IFSs}(X) \times \operatorname{IFSs}(X) \rightarrow[0,1] . d(A, B)$ is said to be an intuitive distance between $A$ and $B$ if $d(A, B)$ satisfies the following properties:

(P1) $0 \leq d(A, B) \leq 1$;

(P2) $d(A, B)=0$ if and only if $A=B$ and $\pi_{A}(x)=\pi_{B}(x)=$ 0 ;

(P3) $d(A, B)=1$ if and only if both $A$ and $B$ are crisp sets and $A=B^{C}$;

(P4) $d(A, B)=d(B, A)$;

(P5) $d(A, C) \leq d(A, B)+d(B, C)$ for any $A, B, C \in \operatorname{IFSs}(X)$;

(P6) if $A \subseteq B \subseteq C$, then $d(B, C) \leq d(A, C)$ and $d(A, B) \leq$ $d(A, C)$

(P7) if $A=B$ and $C=D$, then

(i) $d(A, B)>d(C, D)$ when $\pi_{A}(x)+\pi_{B}(x)>$ $\pi_{C}(x)+\pi_{D}(x)$

(ii) $d(A, B)<d(C, D)$ when $\pi_{A}(x)+\pi_{B}(x)<$ $\pi_{C}(x)+\pi_{D}(x)$ 
(iii) $d(A, B)=d(C, D)$ when $\pi_{A}(x)+\pi_{B}(x)=$ $\pi_{C}(x)+\pi_{D}(x)$.

The above definition is a development for Definition 5. On the one hand, some properties are introduced to make the definition stronger: (P3) is a more precise condition for the endpoint of distance $d(A, B)=1$; (P5) is a new strong property condition, which requires distance to meet triangle inequality. On the other hand, the definition highlights the characteristics of intuitionistic fuzzy information by reinforcing the existing property condition (P2), as well as adding a new property condition (P7). The intuitive distance not only meets the most general properties of traditional distance, but also satisfies a special property: as long as the hesitant index is not zero, even if two IFSs are equal in value, the distance between them is not zero. And the higher the hesitant index, the greater the distance.

Then, we propose a new distance measure. Let $A=$ $\left\langle x, u_{A}(x), v_{A}(x)\right\rangle, B=\left\langle x, u_{B}(x), v_{B}(x)\right\rangle$ be two IFSs in the universe of discourse $X$, and denote $X=\left\{x_{1}, x_{2}, \ldots, x_{n}\right\}$.

$$
\begin{aligned}
d_{L}(A, B) & =\frac{1}{3 n} \sum_{i=1}^{n}\left[\theta_{1}\left(x_{i}\right)+\theta_{2}\left(x_{i}\right)+\theta_{3}\left(x_{i}\right)\right] \\
\theta_{1}\left(x_{i}\right) & =\frac{\left|u_{A}\left(x_{i}\right)-u_{B}\left(x_{i}\right)\right|+\left|v_{A}\left(x_{i}\right)-v_{B}\left(x_{i}\right)\right|+\left|\left(u_{A}\left(x_{i}\right)+1-v_{A}\left(x_{i}\right)\right)-\left(u_{B}\left(x_{i}\right)+1-v_{B}\left(x_{i}\right)\right)\right|}{2}, \\
\theta_{2}\left(x_{i}\right) & =\frac{\pi_{A}\left(x_{i}\right)+\pi_{B}\left(x_{i}\right)}{2}, \\
\theta_{3}\left(x_{i}\right) & =\max \left(\left|u_{A}\left(x_{i}\right)-u_{B}\left(x_{i}\right)\right|,\left|v_{A}\left(x_{i}\right)-v_{B}\left(x_{i}\right)\right| \frac{\left|\pi_{A}\left(x_{i}\right)-\pi_{B}\left(x_{i}\right)\right|}{2}\right) .
\end{aligned}
$$

The structure of $d_{L}(A, B)$ is mainly related to two aspects. One is to take the differences of IFS parameters into account, which is similar to the traditional distance. It includes differences between memberships $u_{A}\left(x_{i}\right)$ and $u_{B}\left(x_{i}\right)$, nonmemberships $v_{A}\left(x_{i}\right)$ and $v_{B}\left(x_{i}\right)$, hesitance indexes $\pi_{A}\left(x_{i}\right)$ and $\pi_{B}\left(x_{i}\right)$, and the differences between median values of intervals $\left(u_{A}\left(x_{i}\right)+1-v_{A}\left(x_{i}\right)\right) / 2$ and $\left(u_{B}\left(x_{i}\right)+1-v_{B}\left(x_{i}\right)\right) / 2$. The second is to satisfy the new requirements of intuitive distance, taking the degree of hesitancy into account. $\theta_{2}\left(x_{i}\right)$ aims to reflect the waver of uncertain information. The higher the degree of nonspecificity of intuitionistic fuzzy information, the greater the possibility of existing differences between them. Then, we have the following theorem.

Theorem 7. $d_{L}(A, B)$ is an intuitive distance between IFSs $A$ and $B$ in the universe of discourse $X=\left\{x_{1}, x_{2}, \ldots, x_{n}\right\}$.

Proof. It is easy to see that $d_{L}(A, B)$ satisfies (P4) and (P7) of Definition 6. Therefore, we shall prove that $d_{L}(A, B)$ satisfies (P1), (P2), (P3), (P5), and (P6).

(P1) Let $A$ and $B$ be two IFSs; we can write the relational expression as follows:

$$
\begin{aligned}
0 \leq & \theta_{1}\left(x_{i}\right)+\theta_{2}\left(x_{i}\right)=\left(\left|u_{A}\left(x_{i}\right)-u_{B}\left(x_{i}\right)\right|\right. \\
& +\left|v_{A}\left(x_{i}\right)-v_{B}\left(x_{i}\right)\right| \\
& +\left|\left(u_{A}\left(x_{i}\right)+1-v_{A}\left(x_{i}\right)\right)-\left(u_{B}\left(x_{i}\right)+1-v_{B}\left(x_{i}\right)\right)\right| \\
& \left.+\pi_{A}\left(x_{i}\right)+\pi_{B}\left(x_{i}\right)\right) \times(2)^{-1}=\left(\left|u_{A}\left(x_{i}\right)-u_{B}\left(x_{i}\right)\right|\right. \\
& +\left|v_{A}\left(x_{i}\right)-v_{B}\left(x_{i}\right)\right| \\
& +\left|\left(u_{A}\left(x_{i}\right)-u_{B}\left(x_{i}\right)\right)-\left(v_{A}\left(x_{i}\right)-v_{B}\left(x_{i}\right)\right)\right|+2
\end{aligned}
$$

$$
\begin{aligned}
& \left.-u_{A}\left(x_{i}\right)-u_{B}\left(x_{i}\right)-v_{A}\left(x_{i}\right)-v_{B}\left(x_{i}\right)\right) \times(2)^{-1} \\
& \leq\left(\left|u_{A}\left(x_{i}\right)-u_{B}\left(x_{i}\right)\right|+\left|v_{A}\left(x_{i}\right)-v_{B}\left(x_{i}\right)\right|\right. \\
& +\left|u_{A}\left(x_{i}\right)-u_{B}\left(x_{i}\right)\right|+\left|v_{A}\left(x_{i}\right)-v_{B}\left(x_{i}\right)\right|+2 \\
& \left.-u_{A}\left(x_{i}\right)-u_{B}\left(x_{i}\right)-v_{A}\left(x_{i}\right)-v_{B}\left(x_{i}\right)\right) \times(2)^{-1} \\
& =\left(2\left|u_{A}\left(x_{i}\right)-u_{B}\left(x_{i}\right)\right|-\left(u_{A}\left(x_{i}\right)+u_{B}\left(x_{i}\right)\right)\right. \\
& \left.+2\left|v_{A}\left(x_{i}\right)-v_{B}\left(x_{i}\right)\right|-\left(v_{A}\left(x_{i}\right)+v_{B}\left(x_{i}\right)\right)+2\right) \\
& \times(2)^{-1} \leq\left(2\left(u_{A}\left(x_{i}\right)+u_{B}\left(x_{i}\right)\right)\right. \\
& -\left(u_{A}\left(x_{i}\right)+u_{B}\left(x_{i}\right)\right)+2\left(v_{A}\left(x_{i}\right)+v_{B}\left(x_{i}\right)\right) \\
& \left.-\left(v_{A}\left(x_{i}\right)+v_{B}\left(x_{i}\right)\right)+2\right) \times(2)^{-1} \\
& =\frac{u_{A}\left(x_{i}\right)+u_{B}\left(x_{i}\right)+v_{A}\left(x_{i}\right)+v_{B}\left(x_{i}\right)+2}{2} \\
& \leq \frac{1+1+2}{2}=2 . \\
& =\frac{\left(u_{A}\left(x_{i}\right)+v_{A}\left(x_{i}\right)\right)+\left(u_{B}\left(x_{i}\right)+v_{B}\left(x_{i}\right)\right)+2}{2} \\
& \leq
\end{aligned}
$$

It is known that

$$
\begin{aligned}
0 & \leq \theta_{3}\left(x_{i}\right)=\max \left(\left|u_{A}\left(x_{i}\right)-u_{B}\left(x_{i}\right)\right|,\right. \\
& \left.\left|v_{A}\left(x_{i}\right)-v_{B}\left(x_{i}\right)\right|, \frac{\left|\pi_{A}\left(x_{i}\right)-\pi_{B}\left(x_{i}\right)\right|}{2}\right) \leq 1 .
\end{aligned}
$$


Taking (11) and (12) into account, it is not difficult to find that

$$
0 \leq \theta_{1}\left(x_{i}\right)+\theta_{2}\left(x_{i}\right)+\theta_{3}\left(x_{i}\right) \leq 3
$$

And therefore we have

$$
\begin{aligned}
0 & \leq d_{L}(A, B)=\frac{1}{3 n} \sum_{i=1}^{n}\left[\theta_{1}\left(x_{i}\right)+\theta_{2}\left(x_{i}\right)+\theta_{3}\left(x_{i}\right)\right] \\
& \leq \frac{3}{3}=1 .
\end{aligned}
$$

(P2) Let $A$ and $B$ be two IFSs; the following relational expression can be written:

$$
\begin{aligned}
d_{L}(A, B) & =0 \\
& \mathbb{1} \\
u_{A}\left(x_{i}\right) & =u_{B}\left(x_{i}\right), \\
v_{A}\left(x_{i}\right) & =v_{B}\left(x_{i}\right), \\
\pi_{A}\left(x_{i}\right)+\pi_{B}\left(x_{i}\right) & =0 \\
& \Uparrow \\
A(x) & =B(x), \\
\pi_{A}(x) & =\pi_{B}(x)=0 .
\end{aligned}
$$

Thus, $d_{L}(A, B)$ satisfies (P2) of Definition 6 .
(P3) Let $A$ and $B$ be two IFSs. Taking (11) and (12) into account, the following relational expressions can be written:

$$
\begin{aligned}
& d_{L}(A, B)=1 \\
& \mathbb{I} \\
& \theta_{1}\left(x_{i}\right)+\theta_{2}\left(x_{i}\right)=2, \\
& \theta_{3}\left(x_{i}\right)=1
\end{aligned}
$$

I

$$
\begin{aligned}
& \frac{u_{A}\left(x_{i}\right)+u_{B}\left(x_{i}\right)+v_{A}\left(x_{i}\right)+v_{B}\left(x_{i}\right)+2}{2}=2, \\
& \max \left(\left|u_{A}\left(x_{i}\right)-u_{B}\left(x_{i}\right)\right|,\left|v_{A}\left(x_{i}\right)-v_{B}\left(x_{i}\right)\right|,\right.
\end{aligned}
$$

$$
\left.\frac{\left|\pi_{A}\left(x_{i}\right)-\pi_{B}\left(x_{i}\right)\right|}{2}\right)=1
$$

$\mathbb{1}$

$$
\begin{aligned}
& A(x)=(1,0,0), \\
& B(x)=(0,1,0) \\
& \text { or } A(x)=(0,1,0), \\
& B(x)=(1,0,0) .
\end{aligned}
$$

Thus, $d_{L}(A, B)$ satisfies (P3) of Definition 6 .

(P5) Let $A, B$, and $C$ be three IFSs; the distances between $A$ and $B, B$ and $C$, and $A$ and $C$ are the following:

$$
\begin{aligned}
& d_{L}(A, B)=\frac{1}{3 n} \sum_{i=1}^{n}\left[\frac{\left|u_{A}\left(x_{i}\right)-u_{B}\left(x_{i}\right)\right|+\left|v_{A}\left(x_{i}\right)-v_{B}\left(x_{i}\right)\right|+\left|\left(u_{A}\left(x_{i}\right)+1-v_{A}\left(x_{i}\right)\right)-\left(u_{B}\left(x_{i}\right)+1-v_{B}\left(x_{i}\right)\right)\right|}{2}\right. \\
& \left.+\frac{\pi_{A}\left(x_{i}\right)+\pi_{B}\left(x_{i}\right)}{2}+\max \left(\left|u_{A}\left(x_{i}\right)-u_{B}\left(x_{i}\right)\right|,\left|v_{A}\left(x_{i}\right)-v_{B}\left(x_{i}\right)\right|, \frac{\left|\pi_{A}\left(x_{i}\right)-\pi_{B}\left(x_{i}\right)\right|}{2}\right)\right], \\
& d_{L}(B, C)=\frac{1}{3 n} \sum_{i=1}^{n}\left[\frac{\left|u_{B}\left(x_{i}\right)-u_{C}\left(x_{i}\right)\right|+\left|v_{B}\left(x_{i}\right)-v_{C}\left(x_{i}\right)\right|+\left|\left(u_{B}\left(x_{i}\right)+1-v_{B}\left(x_{i}\right)\right)-\left(u_{C}\left(x_{i}\right)+1-v_{C}\left(x_{i}\right)\right)\right|}{2}\right. \\
& \left.\quad+\frac{\pi_{B}\left(x_{i}\right)+\pi_{C}\left(x_{i}\right)}{2}+\max \left(\left|u_{B}\left(x_{i}\right)-u_{C}\left(x_{i}\right)\right|,\left|v_{B}\left(x_{i}\right)-v_{C}\left(x_{i}\right)\right|, \frac{\left|\pi_{B}\left(x_{i}\right)-\pi_{C}\left(x_{i}\right)\right|}{2}\right)\right], \\
& d_{L}(A, C)=\frac{1}{3 n} \\
& \left.\quad+\max \left(\left|u_{A}\left(x_{i}\right)-u_{C}\left(x_{i}\right)\right|,\left|v_{A}\left(x_{i}\right)-v_{C}\left(x_{i}\right)\right|, \frac{\left|\pi_{A}\left(x_{i}\right)-\pi_{C}\left(x_{i}\right)\right|}{2}\right)\right] . \\
& \quad \sum_{i=1}^{n}\left[\frac{\left|u_{A}\left(x_{i}\right)-u_{C}\left(x_{i}\right)\right|+\left|v_{A}\left(x_{i}\right)-v_{C}\left(x_{i}\right)\right|+\left|\left(u_{A}\left(x_{i}\right)+1-v_{A}\left(x_{i}\right)\right)-\left(u_{C}\left(x_{i}\right)+1-v_{C}\left(x_{i}\right)\right)\right|+\pi_{A}\left(x_{i}\right)+\pi_{C}\left(x_{i}\right)}{2}\right.
\end{aligned}
$$


It is obvious that

$$
\begin{aligned}
& \left|u_{A}\left(x_{i}\right)-u_{B}\left(x_{i}\right)\right|+\left|u_{B}\left(x_{i}\right)-u_{C}\left(x_{i}\right)\right| \geq \mid u_{A}\left(x_{i}\right) \\
& \quad-u_{B}\left(x_{i}\right)+u_{B}\left(x_{i}\right)-u_{C}\left(x_{i}\right)|=| u_{A}\left(x_{i}\right)-u_{C}\left(x_{i}\right) \mid, \\
& \left|v_{A}\left(x_{i}\right)-v_{B}\left(x_{i}\right)\right|+\left|v_{B}\left(x_{i}\right)-v_{C}\left(x_{i}\right)\right| \geq \mid v_{A}\left(x_{i}\right) \\
& \quad-v_{B}\left(x_{i}\right)+v_{B}\left(x_{i}\right)-v_{C}\left(x_{i}\right)|=| v_{A}\left(x_{i}\right)-v_{C}\left(x_{i}\right) \mid \\
& \left|\left(u_{A}\left(x_{i}\right)+1-v_{A}\left(x_{i}\right)\right)-\left(u_{B}\left(x_{i}\right)+1-v_{B}\left(x_{i}\right)\right)\right| \\
& \quad+\mid\left(u_{B}\left(x_{i}\right)+1-v_{B}\left(x_{i}\right)\right) \\
& \quad-\left(u_{C}\left(x_{i}\right)+1-v_{C}\left(x_{i}\right)\right)|=| u_{A}\left(x_{i}\right)+v_{B}\left(x_{i}\right) \\
& \quad-u_{B}\left(x_{i}\right)-v_{A}\left(x_{i}\right)|+| u_{B}\left(x_{i}\right)+v_{C}\left(x_{i}\right)-u_{C}\left(x_{i}\right) \\
& \quad-v_{B}\left(x_{i}\right)|\geq| u_{A}\left(x_{i}\right)+v_{B}\left(x_{i}\right)-u_{B}\left(x_{i}\right)-v_{A}\left(x_{i}\right) \\
& \quad+u_{B}\left(x_{i}\right)+v_{C}\left(x_{i}\right)-u_{C}\left(x_{i}\right)-v_{B}\left(x_{i}\right)|=| u_{A}\left(x_{i}\right)
\end{aligned}
$$

$$
\begin{aligned}
& -v_{A}\left(x_{i}\right)+v_{C}\left(x_{i}\right)-u_{C}\left(x_{i}\right) \mid \\
& =\mid\left(u_{A}\left(x_{i}\right)+1-v_{A}\left(x_{i}\right)\right) \\
& -\left(u_{C}\left(x_{i}\right)+1-v_{C}\left(x_{i}\right)\right) \mid
\end{aligned}
$$$$
\left|\pi_{A}\left(x_{i}\right)-\pi_{B}\left(x_{i}\right)\right|+\left|\pi_{B}\left(x_{i}\right)-\pi_{C}\left(x_{i}\right)\right| \geq \mid \pi_{A}\left(x_{i}\right)
$$$$
-\pi_{B}\left(x_{i}\right)+\pi_{B}\left(x_{i}\right)-\pi_{C}\left(x_{i}\right)|=| \pi_{A}\left(x_{i}\right)
$$$$
-\pi_{C}\left(x_{i}\right) \mid
$$$$
\frac{\pi_{A}\left(x_{i}\right)+\pi_{B}\left(x_{i}\right)+\pi_{B}\left(x_{i}\right)+\pi_{C}\left(x_{i}\right)}{2} \geq \frac{\pi_{A}+\pi_{C}}{2} .
$$

Therefore, we have $d_{L}(A, B)+d_{L}(B, C) \geq d_{L}(A, C)$.

(P6) Let $A, B$, and $C$ be three IFSs; if $A \subseteq B \subseteq C$, then we have $u_{A}\left(x_{i}\right) \leq u_{B}\left(x_{i}\right) \leq u_{C}\left(x_{i}\right), v_{A}\left(x_{i}\right) \geq v_{B}\left(x_{i}\right) \geq$ $v_{C}\left(x_{i}\right)$. The following equations are given out:

$$
\begin{aligned}
& d_{L}(A, B)=\frac{1}{3 n} \sum_{i=1}^{n}\left[\frac{u_{B}\left(x_{i}\right)-u_{A}\left(x_{i}\right)+v_{A}\left(x_{i}\right)-v_{B}\left(x_{i}\right)+u_{B}\left(x_{i}\right)-u_{A}\left(x_{i}\right)+v_{A}\left(x_{i}\right)-v_{B}\left(x_{i}\right)+\pi_{A}\left(x_{i}\right)+\pi_{B}\left(x_{i}\right)}{2}\right. \\
& \left.+\max \left(u_{B}\left(x_{i}\right)-u_{A}\left(x_{i}\right), v_{A}\left(x_{i}\right)-v_{B}\left(x_{i}\right), \frac{\left|\pi_{A}\left(x_{i}\right)-\pi_{B}\left(x_{i}\right)\right|}{2}\right)\right]=\frac{1}{3 n} \\
& \cdot \sum_{i=1}^{n}\left[\frac{u_{B}\left(x_{i}\right)-u_{A}\left(x_{i}\right)+v_{A}\left(x_{i}\right)-v_{B}\left(x_{i}\right)+u_{B}\left(x_{i}\right)-u_{A}\left(x_{i}\right)+v_{A}\left(x_{i}\right)-v_{B}\left(x_{i}\right)+2-u_{A}\left(x_{i}\right)-u_{B}\left(x_{i}\right)-v_{A}\left(x_{i}\right)-v_{B}\left(x_{i}\right)}{2}\right. \\
& \left.+\max \left(u_{B}\left(x_{i}\right)-u_{A}\left(x_{i}\right), v_{A}\left(x_{i}\right)-v_{B}\left(x_{i}\right), \frac{\left|u_{B}\left(x_{i}\right)-u_{A}\left(x_{i}\right)+v_{B}\left(x_{i}\right)-v_{A}\left(x_{i}\right)\right|}{2}\right)\right]=\frac{1}{3 n} \\
& \cdot \sum_{i=1}^{n}\left[\frac{u_{B}\left(x_{i}\right)-3 u_{A}\left(x_{i}\right)+v_{A}\left(x_{i}\right)-3 v_{B}\left(x_{i}\right)}{2}+\max \left(u_{B}\left(x_{i}\right)-u_{A}\left(x_{i}\right), v_{A}\left(x_{i}\right)-v_{B}\left(x_{i}\right)\right)\right] \text {, } \\
& d_{L}(A, C)=\frac{1}{3 n} \sum_{i=1}^{n}\left[\frac{u_{C}\left(x_{i}\right)-u_{A}\left(x_{i}\right)+v_{A}\left(x_{i}\right)-v_{C}\left(x_{i}\right)+u_{C}\left(x_{i}\right)-u_{A}\left(x_{i}\right)+v_{A}\left(x_{i}\right)-v_{C}\left(x_{i}\right)+\pi_{A}\left(x_{i}\right)+\pi_{C}\left(x_{i}\right)}{2}\right. \\
& \left.+\max \left(u_{C}\left(x_{i}\right)-u_{A}\left(x_{i}\right), v_{A}\left(x_{i}\right)-v_{C}\left(x_{i}\right), \frac{\left|\pi_{A}\left(x_{i}\right)-\pi_{C}\left(x_{i}\right)\right|}{2}\right)\right]=\frac{1}{3 n} \\
& \cdot \sum_{i=1}^{n}\left[\frac{u_{C}\left(x_{i}\right)-u_{A}\left(x_{i}\right)+v_{A}\left(x_{i}\right)-v_{C}\left(x_{i}\right)+u_{C}\left(x_{i}\right)-u_{A}\left(x_{i}\right)+v_{A}\left(x_{i}\right)-v_{C}\left(x_{i}\right)+2-u_{A}\left(x_{i}\right)-u_{C}\left(x_{i}\right)-v_{A}\left(x_{i}\right)-v_{C}\left(x_{i}\right)}{2}\right. \\
& \left.+\max \left(u_{C}\left(x_{i}\right)-u_{A}\left(x_{i}\right), v_{A}\left(x_{i}\right)-v_{C}\left(x_{i}\right), \frac{\left|u_{C}\left(x_{i}\right)-u_{A}\left(x_{i}\right)+v_{C}\left(x_{i}\right)-v_{A}\left(x_{i}\right)\right|}{2}\right)\right]=\frac{1}{3 n} \\
& \cdot \sum_{i=1}^{n}\left[\frac{u_{C}\left(x_{i}\right)-3 u_{A}\left(x_{i}\right)+v_{A}\left(x_{i}\right)-3 v_{C}\left(x_{i}\right)}{2}+\max \left(u_{C}\left(x_{i}\right)-u_{A}\left(x_{i}\right), v_{A}\left(x_{i}\right)-v_{C}\left(x_{i}\right)\right)\right] \text {. }
\end{aligned}
$$

We know that

$$
\begin{gathered}
u_{C}\left(x_{i}\right)-3 v_{C}\left(x_{i}\right) \geq u_{B}\left(x_{i}\right)-3 v_{B}\left(x_{i}\right), \\
u_{C}\left(x_{i}\right)-u_{A}\left(x_{i}\right) \geq u_{B}\left(x_{i}\right)-u_{A}\left(x_{i}\right), \\
v_{A}\left(x_{i}\right)-v_{C}\left(x_{i}\right) \geq v_{A}\left(x_{i}\right)-v_{B}\left(x_{i}\right) .
\end{gathered}
$$

It means that

$$
d_{L}(A, B) \leq d_{L}(A, C)
$$

Similarly, it is easy to prove that

$$
d_{L}(B, C) \leq d_{L}(A, C) .
$$

Thus, $d_{L}(A, B)$ satisfies (P6) of Definition 6 . 
TABLE 1: Test intuitionistic fuzzy sets (IFSs).

\begin{tabular}{lccccccc}
\hline & \multicolumn{7}{c}{ Test IFSs } \\
& 1 & 2 & 3 & 4 & 5 & 6 & 7 \\
\hline$A=\left(u_{A}, v_{A}\right)$ & $(1,0)$ & $(0,0)$ & $(0.4,0.2)$ & $(0.3,0.3)$ & $(0.3,0.4)$ & $(0.1,0.2)$ & $(0.4,0.2)$ \\
$B=\left(u_{B}, v_{B}\right)$ & $(0,0)$ & $(0.5,0.5)$ & $(0.5,0.3)$ & $(0.4,0.4)$ & $(0.4,0.3)$ & $(0.1,0.2)$ & $(0.5,0.2)$ \\
\hline
\end{tabular}

TABLE 2: The comparison of distance measures (counterintuitive cases are in bold italic type).

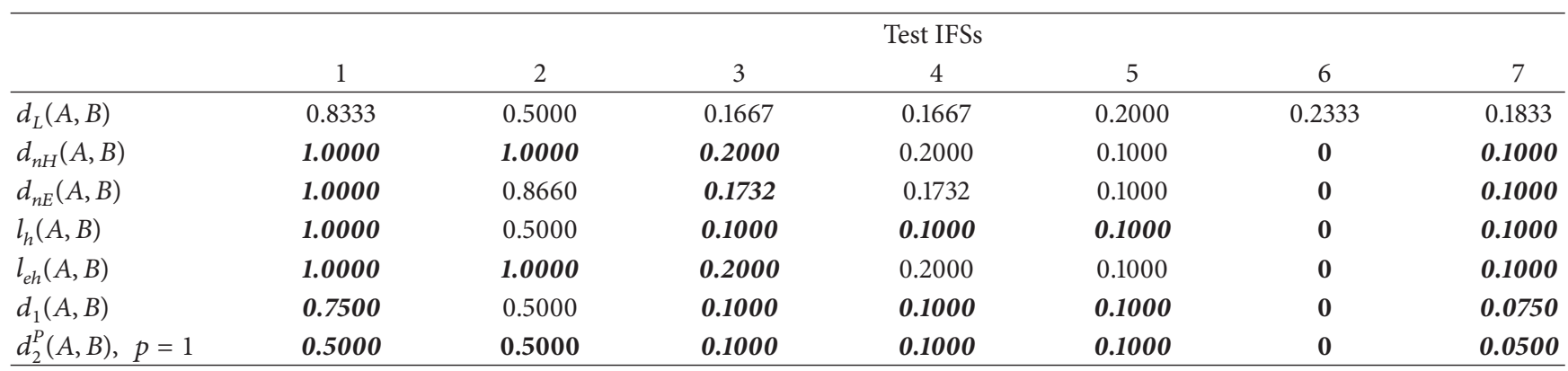

That is to say, $d_{L}(A, B)$ is an intuitive distance between IFSs $A$ and $B$ since it satisfies (P1)-(P7).

\subsection{A Comparison of Distance Measures for IFSs Based on} an Artificial Benchmark. When a new distance measure is proposed, it is always accompanied with explanations of overcoming counterintuitive cases of other methods and these cases are usually illustrated by single-element IFSs. In [30], Li et al. summarized counterintuitive cases proposed by previous literature and constituted an artificial benchmark with six different pairs of single-element IFSs, which has been widely used in the test of distance and similarity measures [31, 44-49]. Although these cases cannot represent all counterintuitive situations, they are typical and representative. In [31], Papakostas et al. suggested that any proposed measures should be tested by the artificial benchmark to avoid counterintuitive cases. To illustrate the effectiveness of the proposed distance measure, all the test IFSs of the artificial benchmark are applied to compare the proposed distance measure to the widely used distance measures. In addition, in order to reflect the characteristics of intuitionistic fuzzy information, a new pair of single-element IFSs as illustrated in Section 3.1 is added to the artificial benchmark test set. Table 1 shows the test IFSs of extended artificial benchmark.

Table 2 provides a comprehensive comparison of the distance measures for IFSs with counterintuitive cases. It is apparent that the property condition (P3) is not met by $d_{n H}$, $d_{n E}, l_{h}, l_{e h}$, because the distances calculated by these measures are equal to 1 when $\{A=(x, 1,0), B=(x, 0,0)\}$. Similarly, the property condition (P3) is also not satisfied by $d_{n H}, l_{e h}$ when $\{A=(x, 0,0), B=(x, 0.5,0.5)\}$. The distance measures $d_{n H}, l_{e h}$, and $d_{2}^{P}, p=1$, indicate that the distances of the 1 st test IFSs and the 2nd test IFSs are identical, which does not seem to be reasonable. Distance measures $l_{h}, d_{1}$, and $d_{2}^{P}, p=1$, claim that the distances of the 4 th test IFSs and the 5 th test IFSs show the same value of 0.1 , which indicates that there are not sufficient abilities to distinguish positive difference from negative difference. The distance of 3rd test
IFSs is equal to or greater than the distance of the 7th test IFSs when $d_{n H}, d_{n E}, l_{h}, l_{e h}, d_{1}$, and $d_{2}^{P}, p=1$, are used, which does not seem to be reasonable since IFSs $A, B$, and $C$ are ordered as $C>B>A$ according to the score function and accuracy function given in Definition 2, indicating that the distance between $A$ and $B$ is smaller than that between $A$ and $C$. Furthermore, all of these existing distances claim that the distance of the 6th test IFSs is equal to zero, which does not seem to be reasonable. As a mathematical tool, IFSs can describe the uncertain information greatly, because it adds a hesitant index to describe the state of "both this and that." In this case, we indeed cannot confirm that there is no difference between the information carried by IFSs $A$ and $B$, because the hesitance index includes some nonspecificity information and the proportion of support and opposition is not sure.

Based on analysis in Table 2, it is deduced that the existing distance measures with their own measuring focus can meet all or most of properties condition of distance measure between IFSs; however, most distance measures show counterintuitive cases and may fail to distinguish IFSs accurately in some practical applications. Besides, the proposed distance measure is the only one that has no aforementioned counterintuitive cases as illustrated in Table 2. Furthermore, the proposed distance conforms to all the property requirements of the intuitive distance and the potential difference brought by hesitance index is considered.

\section{IF-VIKOR Method for MADM}

On the basis of new distance measure, this section present stepwise algorithm for proposed IF-VIKOR method.

For a MADM problem with $n$ alternatives $A_{i}(i=$ $1,2, \ldots, m)$, the performance of the alternative $A_{i}$ concerning the attribute $C_{j}(j=1,2, \ldots, n)$ is assessed by a decision organization with several decision-makers $D_{q}(q=1,2, \ldots, l)$. The corresponding weights of attributes are denoted by $w_{j}(j=1,2, \ldots, n), 0 \leq w_{j} \leq 1, \sum_{j=1}^{n} w_{j}=1$, and the weights of DMs are denoted by $\lambda_{q}(q=1,2, \ldots, l), 0 \leq \lambda_{q} \leq 1$, 
$\sum_{q=1}^{l} \lambda_{q}=1$. Inspired by the classical VIKOR method and its extensions, the intuitive distance based VIKOR method can be given for MADM problem with intuitionistic fuzzy information; it includes seven steps.

Step 1. Generate assessment information. Assume that DMs $D_{q}(q=1,2, \ldots, l)$ provide their opinion of the alternatives $A_{i}$ concerning each attribute $C_{j}$ by using IFNs $x_{i j}^{q}=$ $\left(u_{i j}^{q}, v_{i j}^{q}, \pi_{i j}^{q}\right)$ or linguistic values represented by IFNs. Then, the assessments given by $D_{q}$ can be expressed as

$$
D^{(q)}=\left[\begin{array}{cccc}
x_{11}^{(q)} & x_{12}^{(q)} & \cdots & x_{1 n}^{(q)} \\
x_{21}^{(q)} & x_{22}^{(q)} & \cdots & x_{2 n}^{(q)} \\
\vdots & \vdots & \ddots & \vdots \\
x_{m 1}^{(q)} & x_{m 2}^{(q)} & \cdots & x_{m n}^{(q)}
\end{array}\right] .
$$

Step 2. Acquire the weights of DMs. According to the degree of fuzziness and nonspecificity of assessments provided by DMs, in this step, DM weight $\lambda_{q}(q=1,2, \ldots, l)$ can be acquired by intuitionistic fuzzy entropy measure objectively. The lower the degree of fuzziness and nonspecificity is, the smaller the entropy is and the bigger the weight of DM is, and vice versa. By using (5), the intuitionistic fuzzy entropy of assessments provided by $D_{q}$ can be obtained as follows:

$$
E_{q}=\sum_{i=1}^{m} \sum_{j=1}^{n} \frac{\min \left(u_{i j}^{(q)}, v_{i j}^{(q)}\right)+\pi_{i j}^{(q)}}{\max \left(u_{i j}^{(q)}, v_{i j}^{(q)}\right)+\pi_{i j}^{(q)}} .
$$

Then, the weight of DM $D_{q}$ can be defined as follows:

$$
\lambda_{q}=\frac{1-E_{q}}{l-\sum_{q=1}^{l} E_{q}},
$$

where $l$ is the number of DMs.

Step 3. Establish the aggregated intuitionistic fuzzy decision matrix. By using (4), all individual decision matrixes $D^{(q)}$ can be converted into an aggregated decision matrix as follows:

$$
D=\left[\begin{array}{cccc}
x_{11} & x_{12} & \cdots & x_{1 n} \\
x_{21} & x_{22} & \cdots & x_{2 n} \\
\vdots & \vdots & \ddots & \vdots \\
x_{m 1} & x_{m 2} & \cdots & x_{m n}
\end{array}\right],
$$

where $x_{i j}=\left(u_{i j}, v_{i j}, \pi_{i j}\right), u_{i j}=1-\prod_{q=1}^{l}\left(1-u_{i j}^{q}\right)^{\lambda_{q}}, v_{i j}=$ $\prod_{q=1}^{l}\left(v_{i j}^{q}\right)^{\lambda_{q}}, \pi_{i j}=1-u_{i j}-v_{i j}$.

Step 4. Acquire the weights of attributes. Similar to Step 2, the unknown weight of attribute $w_{j}(j=1,2, \ldots, n)$ can be determined by entropy measure to effectively reduce the subjective randomness. By using (5), we can obtain the entropy with respect to $C_{j}$ :

$$
E_{j}=\frac{1}{m} \sum_{i=1}^{m} \frac{\min \left(u_{i j}, v_{i j}\right)+\pi_{i j}}{\max \left(u_{i j}, v_{i j}\right)+\pi_{i j}} .
$$

Then, the weight of attribute $C_{j}$ can be defined as follows:

$$
w_{j}=\frac{1-E_{j}}{n-\sum_{j=1}^{n} E_{j}},
$$

where $n$ is the number of attributes.

Step 5. Find the best and worst value. The best value $x_{j}^{+}$and the worst value $x_{j}^{-}$for each attribute $C_{j}$ can be defined as follows:

$$
\begin{aligned}
& x_{j}^{+}= \begin{cases}\max _{i=1,2, \ldots, m} x_{i j}, & \text { for benefit attribute } C_{j} \\
\min _{i=1,2, \ldots, m} x_{i j}, & \text { for cost attribute } C_{j},\end{cases} \\
& \qquad(j=1,2, \ldots, n) . \\
& x_{j}^{-}= \begin{cases}\min _{i=1,2, \ldots, m} x_{i j}, & \text { for benefit attribute } C_{j} \\
\max _{i=1,2, \ldots, m} x_{i j}, & \text { for cos t attribute } C_{j},\end{cases} \\
& (j=1,2, \ldots, n)
\end{aligned}
$$

Step 6. Compute the values $S_{i}, R_{i}$, and $Q_{i}$. Three key values of IF-VIKOR method, the group utility value $S_{i}$, the individual regret value $R_{i}$, and the compromise value $Q_{i}$, are computed in light of the intuitive distance measure for each alternative:

$$
\begin{aligned}
S_{i} & =\sum_{j=1}^{n} w_{j}\left(\frac{d\left(x_{j}^{+}, x_{i j}\right)}{d\left(x_{j}^{+}, x_{j}^{-}\right)}\right), \\
R_{i} & =\max _{j} w_{j}\left(\frac{d\left(x_{j}^{+}, x_{i j}\right)}{d\left(x_{j}^{+}, x_{j}^{-}\right)}\right), \\
Q_{i} & =\gamma\left(\frac{S_{i}-S^{*}}{S^{-}-S^{*}}\right)+(1-\gamma)\left(\frac{R_{i}-R^{*}}{R^{-}-R^{*}}\right),
\end{aligned}
$$

where $S^{-}=\max _{i} S_{i}, S^{*}=\min _{i} S_{i}, R^{-}=\max _{i} R_{i}, R^{*}=$ $\min _{i} R_{i} \cdot \gamma$ is the coefficient of decision mechanism. The compromise solution can be elected by majority $(\gamma>0.5)$, consensus $(\gamma=0.5)$, or veto $(\gamma<0.5)$.

Step 7. Rank the alternatives and derive the compromise solution. Sort $S_{i}, R_{i}$, and $Q_{i}$ in ascending order and generate three ranking lists $S_{[\cdot]}, R_{[\cdot]}$, and $Q_{[\cdot]}$. Then, the alternative $A^{(1)}$ that ranks the best in $Q_{[\cdot]}$ (minimum value) and fulfills following two conditions simultaneously would be the compromise solution.

Condition 1 (acceptable advantage). One has

$$
Q\left(A^{(2)}\right)-Q\left(A^{(1)}\right) \geq \frac{1}{m-1}
$$

where $A^{(1)}$ and $A^{(2)}$ are the top two alternatives in $Q_{i}$. 
Condition 2 (acceptable stability). The alternative $A^{(1)}$ should also be the best ranked by $S_{i}$ and $R_{i}$.

If the above conditions cannot be satisfied simultaneously, there exist multiple compromise solutions:

(1) alternatives $A^{(1)}$ and $A^{(2)}$ if only Condition 2 is not satisfied;

(2) alternatives $A^{(1)}, A^{(2)}, \ldots, A^{(u)}$ if Condition 1 is not satisfied, where $A^{(u)}$ is established by the relation $Q\left(A^{(u)}\right)-Q\left(A^{(1)}\right)<1 /(m-1)$ for the maximum.

\section{Application Examples}

5.1. ERP Selection Problem. In recent years, enterprise resource planning (ERP) system has become a powerful tool for enterprises to improve their operating performance and competitiveness. However, ERP projects report an unusually high failure rate and sometimes imperil implementers' core operation due to their high costs and wide range of configuration. Consequently, selecting the ERP system which fit the enterprise would be a critical step to success. Considering a situation that one high-tech manufacturing enterprise is trying to implement ERP system with four alternatives $A_{1}$, $A_{2}, A_{3}$, and $A_{4}$, three DMs of $D_{1}, D_{2}, D_{3}$ are employed to evaluate these alternatives from five main aspects as follows:

$C_{1}$ : Functionality and reliability, which involve suitability, accuracy, security, functionality compliance, maturity, recoverability, fault tolerance, and reliability compliance.

$\mathrm{C}_{2}$ : Usability and efficiency, which involve understandability, learnability, operability, attractiveness, usability compliance, time behavior, resource behavior, and efficiency compliance.

$\mathrm{C}_{3}$ : Maintainability and portability, which involve analyzability, changeability, testability, coexistence, interoperation, maintainability, and portability compliance.
TABLE 3: Linguistic terms for rating the alternatives with IFNs.

\begin{tabular}{lc}
\hline Linguistic variables & IFNs \\
\hline Extremely poor (EP) & $(0.05,0.95,0.00)$ \\
Poor (P) & $(0.20,0.70,0.10)$ \\
Medium poor (MP) & $(0.35,0.55,0.10)$ \\
Medium (M) & $(0.50,0.40,0.10)$ \\
Medium good (MG) & $(0.65,0.25,0.10)$ \\
Good (G) & $(0.80,0.10,0.10)$ \\
Extremely good (EG) & $(0.95,0.05,0.00)$ \\
\hline
\end{tabular}

$C_{4}$ : Supplier services, which involve the quality of training staff, technical support and follow-up services, the level of implementation and standardization, customer satisfaction, supplier credibility, and strength.

$C_{5}$ : The enterprise characteristics, which involve enterprise management, employee support, comprehensive investment cost, internal rate of return, benefit cost ratio, and dynamic payback period.

Since the weights of attributes and DMs are completely unknown, the best alternative would be selected with the information given above. In the following, the proposed IF-VIKOR method is applied to solve this problem. The operation process according to the algorithm developed in Section 4 is given below.

Step 1. Each DM assesses alternative $A_{i}$ concerning attribute $C_{j}$ with linguistic rating variables in Table 3 . Table 4 shows the assessments by three decision-makers.

Step 2. By using (24) and (25), the weights of DMs can be obtained as $\lambda_{1}=0.3220, \lambda_{2}=0.3244, \lambda_{3}=0.3536$.

Step 3. By using (26), we can establish the aggregated decision matrix as follows.

$$
D=\left[\begin{array}{llllll}
(0.6689,0.2193) & (0.8000,0.1000) & (0.3500,0.5500) & (0.7081,0.1857) & (0.5592,0.3388) \\
(0.6062,0.2717) & (0.6495,0.2331) & (0.6071,0.2912) & (0.5000,0.4000) & (0.7562,0.1383) \\
(0.5542,0.3438) & (0.7308,0.1568) & (0.8355,0.1223) & (0.8465,0.1077) & (0.7128,0.1808) \\
(0.6495,0.2331) & (0.6719,0.2168) & (0.6074,0.2908) & (0.5546,0.3434) & (0.5423,0.3491)
\end{array}\right] .
$$

Step 4. By using (27) and (28), the weights of attributes are obtained as $w_{1}=0.1950, w_{2}=0.2129, w_{3}=0.1980, w_{4}=$ $0.1966, w_{5}=0.1976$.

Step 5. By using (29), the best and the worst values of all attribute ratings can be calculated and we have $x_{1}^{+}=(0.6689$, $0.2193), x_{2}^{+}=(0.8000,0.1000), x_{3}^{+}=(0.8355,0.1223), x_{4}^{+}=$ $(0.8465,0.1077), x_{5}^{+}=(0.7562,0.1383), x_{1}^{-}=(0.5542,0.3438)$, $x_{2}^{-}=(0.6495,0.2331), x_{3}^{-}=(0.3500,0.5500), x_{4}^{-}=(0.5000$, $0.4000), x_{5}^{-}=(0.5423,0.3491)$.
Step 6. Without loss of generality, let $\gamma=0.5$. By using (30), the values of $S_{i}, R_{i}$, and $Q_{i}$ for each alternative can be obtained as listed in Table 5.

Step 7. From Table 5, we have $Q_{3}<Q_{1}<Q_{4}<Q_{2}$, which means $A_{3}$ (minimum value) ranks best in terms of $Q$. In addition, $Q_{1}-Q_{3}=0.3298 \geq 0.25$ and $A_{3}$ is also the best ranked by $S_{i}$ and $R_{i}$, which shows that $A_{3}$ is the unique compromise solution for this problem. 
TABLE 4: Rating of the alternatives from DMs.

\begin{tabular}{lcccccccccccc}
\hline Attributes & \multicolumn{3}{c}{ DM1 } & \multicolumn{4}{c}{ DM3 } & \multicolumn{4}{c}{ DM4 } \\
& $A_{1}$ & $A_{2}$ & $A_{3}$ & $A_{4}$ & $A_{1}$ & $A_{2}$ & $A_{3}$ & $A_{4}$ & $A_{1}$ & $A_{2}$ & $A_{3}$ & $A_{4}$ \\
\hline$C_{1}$ & MG & M & MG & MP & G & MP & M & MG & M & G & M & G \\
$C_{2}$ & G & MP & G & G & G & MG & M & M & G & G & G & MG \\
$C_{3}$ & MP & MG & M & M & MP & M & G & MG & MP & MG & EG & MG \\
$C_{4}$ & MG & M & EG & M & G & M & MG & MG & MG & M & G & M \\
$C_{5}$ & M & G & MG & MG & M & G & MG & P & MG & MG & G & MG \\
\hline
\end{tabular}

TABLE 5: The values of $S, R$, and $Q$ for all alternatives by the proposed IF-VIKOR method.

\begin{tabular}{lcccc}
\hline Value & $A_{1}$ & $A_{2}$ & $A_{3}$ & $A_{4}$ \\
\hline$S$ & 0.5470 & 0.6657 & 0.3911 & 0.7175 \\
$R$ & 0.1979 & 0.2127 & 0.1948 & 0.1974 \\
$Q$ & 0.3298 & 0.9065 & 0.0000 & 0.5698 \\
\hline
\end{tabular}

TABLE 6: Linguistic terms for rating the alternatives with trapezoidal fuzzy numbers.

\begin{tabular}{lc}
\hline Linguistic variables & Trapezoidal fuzzy numbers \\
\hline Extremely poor (EP) & $(0,0,1,2)$ \\
Poor (P) & $(1,2,2,3)$ \\
Medium poor (MP) & $(2,3,4,5)$ \\
Medium (M) & $(4,5,5,6)$ \\
Medium good (MG) & $(5,6,7,8)$ \\
Good (G) & $(7,8,8,9)$ \\
Extremely good (EG) & $(8,9,10,10)$ \\
\hline
\end{tabular}

Liu et al. [18] developed the VIKOR method for MADM problem based on trapezoidal fuzzy numbers, which is one of the most commonly used fuzzy numbers. In this method, the weights of DMs or attributes are given artificially and the linguistic variables are represented by trapezoidal fuzzy numbers shown in Table 6. A trapezoidal fuzzy number $\widetilde{A}$ can be denoted as $\left(a_{1}, a_{2}, a_{3}, a_{4}\right)$, where $a_{1}$ and $a_{4}$ are called lower and upper limits of $\widetilde{A}$ and $a_{2}$ and $a_{3}$ are two most promising values. When $a_{2}$ and $a_{3}$ are the same value, the trapezoidal fuzzy number degenerated a triangular fuzzy number. We apply the method [18] in the ERP selection problem to explain the difference between the proposed method and traditional VIKOR method with trapezoidal fuzzy numbers. Assume that the weights of DMs and attributes are $\lambda_{1}=0.3220$, $\lambda_{2}=0.3244, \lambda_{3}=0.3536$ and $w_{1}=0.1950, w_{2}=0.2129$, $w_{3}=0.1980, w_{4}=0.1966, w_{5}=0.1976$, respectively. Through calculation of linguistic assessment information and trapezoidal fuzzy numbers shown in Tables 4 and 6, the values of $S, R$, and $Q$ for all alternatives are obtained as in Table 7. The result shows that the ranking order of alternatives obtained by the method [18] is $A_{3}>A_{1}>A_{4}>A_{2}$, which is in harmony with our proposed method. Although the results obtained from the two VIKOR methods are consistent, the trapezoidal fuzzy numbers are only characterized by a membership function, while IFNs are characterized by a membership function and a nonmembership function, which closely resembles the thinking habit of human beings under the situation of being uncertain and hesitant. Furthermore, the trapezoidal fuzzy numbers need four values to determine the membership distribution, while the IFNs only need two values: membership and nonmembership, and the degree of hesitancy can be automatically generated by 1 minus membership and nonmembership. In general, the computation of trapezoidal fuzzy numbers is large, and the application of IFNs is relatively simple. In addition, the method presented by [18] needs the weight information of DMs and attributes predetermined, whereas these weights are determined objectively using intuitionistic fuzzy entropy in the proposed method, which avoids subjective randomness to some extent.

In [22], Roostaee et al. put forward a hamming distance based IF-VIKOR method. To further illustrate its effectiveness, the proposed method is compared to the IF-VIKOR method presented by [22]. Computational results for the hamming distance based IF-VIKOR method are shown in Table 8 . The result indicates that these two methods reach a consensus that the third ERP system should be implemented by the high-tech manufacturing enterprise.

In this example, it should be noted that the assessments provided by DMs are in low degree of hesitancy. As shown in Tables 3 and 4, the maximum hesitance index with respect to linguistic values is 0.1 , denoting the low degree of nonspecificity (lack of knowledge) for assessments. In this case, both methods can effectively evaluate and sort the alternatives. However, the hamming distance based IFVIKOR method is not always capable of obtaining valid results especially in MADM problem with high degree of nonspecificity. It might generate some counterintuitive cases so that unreasonable results might be obtained. The following example further illustrates such cases.

5.2. Material Handling Selection Problem. To illustrate the superiority of the proposed methods, a comparison between the proposed IF-VIKOR method and the hamming distance based IF-VIKOR method in a material handling selection problem is made. 
TABLE 7: The values of $S, R$, and $Q$ for all alternatives by the trapezoidal fuzzy numbers based VIKOR method.

\begin{tabular}{lcccc}
\hline Value & $A_{1}$ & $A_{2}$ & $A_{3}$ & $A_{4}$ \\
\hline$S$ & 0.3827 & 0.4629 & 0.3231 & 0.5632 \\
$R$ & 0.2135 & 0.2204 & 0.1973 & 0.1996 \\
$Q$ & 0.2736 & 0.7911 & 0.0000 & 0.5052 \\
\hline
\end{tabular}

TABLE 8: The values of $S, R$, and $Q$ for all alternatives by the hamming distance based IF-VIKOR method.

\begin{tabular}{lcccc}
\hline Value & $A_{1}$ & $A_{2}$ & $A_{3}$ & $A_{4}$ \\
\hline$S$ & 0.4495 & 0.5896 & 0.3295 & 0.6569 \\
$R$ & 0.1980 & 0.2129 & 0.1950 & 0.1976 \\
$Q$ & 0.2671 & 0.8972 & 0.0000 & 0.5726 \\
\hline
\end{tabular}

TABLE 9: Rating of the alternatives from decision organization.

\begin{tabular}{lccll}
\hline & $C_{1}$ & $C_{2}$ & $C_{3}$ & $C_{4}$ \\
\hline$A_{1}$ & $(0.1,0.2)$ & $(0.4,0.2)$ & $(0.5,0.2)$ & $(0.2,0.4)$ \\
$A_{2}$ & $(0.2,0.1)$ & $(0.3,0.3)$ & $(0.3,0.5)$ & $(0.5,0.5)$ \\
$A_{3}$ & $(0.0,0.3)$ & $(0.3,0.4)$ & $(0.2,0.3)$ & $(0.5,0.2)$ \\
$A_{4}$ & $(0.4,0.4)$ & $(0.5,0.2)$ & $(0.5,0.2)$ & $(0.2,0.4)$ \\
\hline
\end{tabular}

TABLE 10: The compromise values and ranking results obtained by the hamming distance based IF-VIKOR method and the proposed method in this paper.

\begin{tabular}{lcccc}
\hline Alternative & $\begin{array}{c}\text { Hamming distance based IF-VIKOR method } \\
\text { The values of } Q_{i}\end{array}$ & Ranking orders & \multicolumn{2}{c}{ The method proposed in this paper } \\
The values of $Q_{i}$ & 0.3099 \\
\hline$A_{1}$ & 0 & 1 & 0.7286 & 2 \\
$A_{2}$ & 0.4029 & 2 & 1.0000 & 3 \\
$A_{3}$ & 0.5046 & 3 & 0 & 4 \\
$A_{4}$ & 0.6312 & 4 & & 1 \\
\hline
\end{tabular}

Suppose that a manufacturing company is considering implementing a material handling system. After preliminary screening, four alternatives of $A_{1}, A_{2}, A_{3}$, and $A_{4}$ remain to be further evaluated. Several DMs from the company's technical committee are arranged to evaluate and select the appropriate alternative. They assess the four alternatives according to four conflicting attributes, including investment cost $C_{1}$, operation time $C_{2}$, expansion possibility $C_{3}$, and closeness to market demand $C_{4}$. Due to the lack of experience, time constraints, and other factors, the ratings of alternatives concerning each attribute provided by DMs are represented as IFNs with high degree of hesitancy, listed in Table 9. By using (27) and (28), the weights of attributes are obtained as $w_{1}=0.2426, w_{2}=0.2490, w_{3}=0.2593, w_{4}=$ 0.2490 . Without losing generality, let $\gamma=0.5$. Then, the values of $S_{i}, R_{i}$, and $Q_{i}$ for each alternative can be calculated. Computational results obtained by the hamming distance based IF-VIKOR method and the proposed method in this paper are listed in Table 10. The ranking of alternatives calculated by the hamming distance based IF-VIKOR method is $A_{1}>A_{2}>A_{3}>A_{4}$, reaching a conclusion that $A_{1}$ (minimum value) is the best choice and $A_{4}$ is the worst choice for the material handling selection problem. However, according to the score function and accuracy function, each attribute rating of $A_{1}$ is lower than or equal to that of $A_{4}$, indicating that $A_{4}$ is superior to $A_{1}$, which is contradicted to the ranking results obtained by hamming distance based IFVIKOR method. Instead, our proposed method can overcome the drawback of traditional method and obtain a valid ranking result as $A_{4}>A_{1}>A_{2}>A_{3}$, which means that material handling system $A_{4}$ is the best choice for the manufacturing company.

5.3. Sensitivity Analysis. In intuitionistic fuzzy VIKOR method, $\gamma$, the coefficient of decision mechanism is critical to the ranking results. Hence, a sensitivity analysis is conducted in order to assess the stability of our method in these examples. For each $\gamma$ from 0 to 1 at 0.1 intervals, we calculate the corresponding compromise solution to investigate the influence of different $\gamma$ on the ranking result.

Table 11 shows the sensitivity analysis of ERP selection example. For all the tested values of $\gamma$, three different ranking results are generated including $A_{3}>A_{4}>A_{1}>A_{2}$, $A_{3}>A_{1}>A_{4}>A_{2}$, and $A_{3}>A_{1}>A_{2}>A_{4}$. While the ranking result is indeed affected by $\gamma, A_{3}$ is always the optimal solution. Table 12 shows the sensitivity analysis of material handling system selection example. For all the tested values of $\gamma$, the ranking result remains $A_{4}>A_{1}>A_{2}>A_{3}$ and 
TABLE 11: Rating of the alternatives for different $\gamma$ values (ERP selection example).

\begin{tabular}{|c|c|c|c|c|c|c|}
\hline$\gamma$ & $Q_{1}$ & $Q_{2}$ & $Q_{3}$ & $Q_{4}$ & Ranking & Optimal solution \\
\hline 0 & 0.1676 & 1.0000 & 0 & 0.1397 & $A_{3}>A_{4}>A_{1}>A_{2}$ & $A_{3}$ \\
\hline 0.1 & 0.2000 & 0.9813 & 0.0000 & 0.2257 & $A_{3}>A_{1}>A_{4}>A_{2}$ & $A_{3}$ \\
\hline 0.2 & 0.2325 & 0.9626 & 0.0000 & 0.3117 & $A_{3}>A_{1}>A_{4}>A_{2}$ & $A_{3}$ \\
\hline 0.3 & 0.2649 & 0.9439 & 0.0000 & 0.3978 & $A_{3}>A_{1}>A_{4}>A_{2}$ & $A_{3}$ \\
\hline 0.4 & 0.2974 & 0.9252 & 0.0000 & 0.4838 & $A_{3}>A_{1}>A_{4}>A_{2}$ & $A_{3}$ \\
\hline 0.5 & 0.3298 & 0.9065 & 0.0000 & 0.5698 & $A_{3}>A_{1}>A_{4}>A_{2}$ & $A_{3}$ \\
\hline 0.6 & 0.3622 & 0.8878 & 0.0000 & 0.6559 & $A_{3}>A_{1}>A_{4}>A_{2}$ & $A_{3}$ \\
\hline 0.7 & 0.3947 & 0.8691 & 0.0000 & 0.7419 & $A_{3}>A_{1}>A_{4}>A_{2}$ & $A_{3}$ \\
\hline 0.8 & 0.4271 & 0.8504 & 0.0000 & 0.8279 & $A_{3}>A_{1}>A_{4}>A_{2}$ & $A_{3}$ \\
\hline 0.9 & 0.4596 & 0.8317 & 0.0000 & 0.9140 & $A_{3}>A_{1}>A_{2}>A_{4}$ & $A_{3}$ \\
\hline 1 & 0.4920 & 0.8130 & 0.0000 & 1.0000 & $A_{3}>A_{1}>A_{2}>A_{4}$ & $A_{3}$ \\
\hline
\end{tabular}

TABLE 12: Rating of the alternatives for different $\gamma$ values (material handling selection example).

\begin{tabular}{|c|c|c|c|c|c|c|}
\hline$\gamma$ & $Q_{1}$ & $Q_{2}$ & $Q_{3}$ & $Q_{4}$ & Ranking & Optimal solution \\
\hline 0 & 0.3224 & 0.6299 & 1.0000 & 0 & $A_{4}>A_{1}>A_{2}>A_{3}$ & $A_{4}$ \\
\hline 0.1 & 0.3199 & 0.6496 & 1.0000 & 0 & $A_{4}>A_{1}>A_{2}>A_{3}$ & $A_{4}$ \\
\hline 0.2 & 0.3174 & 0.6694 & 1.0000 & 0 & $A_{4}>A_{1}>A_{2}>A_{3}$ & $A_{4}$ \\
\hline 0.3 & 0.3149 & 0.6891 & 1.0000 & 0 & $A_{4}>A_{1}>A_{2}>A_{3}$ & $A_{4}$ \\
\hline 0.4 & 0.3124 & 0.7089 & 1.0000 & 0 & $A_{4}>A_{1}>A_{2}>A_{3}$ & $A_{4}$ \\
\hline 0.5 & 0.3099 & 0.7286 & 1.0000 & 0 & $A_{4}>A_{1}>A_{2}>A_{3}$ & $A_{4}$ \\
\hline 0.6 & 0.3074 & 0.7484 & 1.0000 & 0 & $A_{4}>A_{1}>A_{2}>A_{3}$ & $A_{4}$ \\
\hline 0.7 & 0.3049 & 0.7682 & 1.0000 & 0 & $A_{4}>A_{1}>A_{2}>A_{3}$ & $A_{4}$ \\
\hline 0.8 & 0.3025 & 0.7879 & 1.0000 & 0 & $A_{4}>A_{1}>A_{2}>A_{3}$ & $A_{4}$ \\
\hline 0.9 & 0.3000 & 0.8077 & 1.0000 & 0 & $A_{4}>A_{1}>A_{2}>A_{3}$ & $A_{4}$ \\
\hline 1 & 0.2975 & 0.8274 & 1.0000 & 0 & $A_{4}>A_{1}>A_{2}>A_{3}$ & $A_{4}$ \\
\hline
\end{tabular}

the optimal solution is $A_{4}$. The sensitivity analysis illustrates how the decision-making strategy would affect the result, and also it indicates that the conclusion arrived from our method is stable and effective.

\section{Conclusion}

Since the VIKOR method is an effective MADM method to reach a compromise solution, and IFSs are an effective tool to depict fuzziness and nonspecificity in assessment information, we combine them and develop a new intuitive distance based IF-VIKOR method. This new method aims at MADM problems with unknown weights of both the DMs and attributes in intuitionistic fuzzy environment. It aggregates assessment information by intuitionistic fuzzy weighted averaging operator, generates weights of DMs and attributes by intuitionistic fuzzy entropy objectively, calculates the group utility and individual regret based on intuitive distance measure, and finally reaches the compromise solution. Two application examples of ERP and material handing selection problem further illustrate each step of this method. Compared with the hamming distance measure used in traditional IF-VIKOR method, the new intuitive distance measure in this method focuses on the fuzziness and nonspecificity of intuitionistic fuzzy information, reflecting not only the difference among the values of intuitionistic fuzzy sets, but also the waver of intuitionistic fuzzy sets. Both the artificial benchmark test and application examples demonstrate its effectiveness and superiority to traditional method. Also, the determination of weights of DMs and attributes using intuitionistic fuzzy entropy can avoid subjective randomness, and sensitivity analysis shows the stability of the proposed method. For future work, the comparison of the proposed VIKOR method with other MADM methods under intuitionistic fuzzy environment, such as the TOPSIS method, the PROMETHEE method, and the ELECTRE method, is worthy of further study and exploration. It would also be interesting to apply the proposed VIKOR method to other MADM problems, such as investment decision and supplier selection.

\section{Conflicts of Interest}

The authors declare that they have no conflicts of interest.

\section{Acknowledgments}

This work was supported by the National Natural Science Foundation of China under Grant 61273275. 


\section{References}

[1] C. L. Hwang and K. Yoon, Multiple Attribute Decision Making: Methods and Applications, Springer, Germany, Berlin, 1981.

[2] S. Opricovic, Multicriteria Optimization of Civil Engineering Systems, Faculty of Civil Engineering, Belgrade, Serbia, 1998.

[3] B. Mareschal and J. P. Vincke, "PROMETHEE: a new family of outranking methods in multi criteria analysis," Brans J.p.operational Research, vol. 84, pp. 477-490, 1984.

[4] R. Benayoun, B. Roy, and B. Sussman, "ELECTRE: "Une méthode pour guider le choix en présence de points de vue multiples," Rev.Franaise Informat.Recherche Opérationnelle, vol. 3, pp. 31-56, 1969.

[5] S. Opricovic and G. H. Tzeng, "Compromise solution by MCDM methods: a comparative analysis of VIKOR and TOPSIS," European Journal of Operational Research, vol. 156, no. 2, pp. 445-455, 2004.

[6] S. Opricovic and G. Tzeng, "Extended VIKOR method in comparison with outranking methods," European Journal of Operational Research, vol. 178, no. 2, pp. 514-529, 2007.

[7] L. Anojkumar, M. Ilangkumaran, and V. Sasirekha, "Comparative analysis of MCDM methods for pipe material selection in sugar industry," Expert Systems with Applications, vol. 41, no. 6, pp. 2964-2980, 2014.

[8] P. P. Mohanty and S. Mahapatra, "A compromise solution by vikor method for ergonomically designed product with optimal set of design characteristics," Procedia Materials Science, vol. 6, pp. 633-640, 2014.

[9] G. Vats and R. Vaish, "Piezoelectric material selection for transducers under fuzzy environment," Journal of Advanced Ceramics, vol. 2, no. 2, pp. 141-148, 2013.

[10] K.-H. Peng and G.-H. Tzeng, "A hybrid dynamic MADM model for problem-improvement in economics and business," Technological and Economic Development of Economy, vol. 19, no. 4, pp. 638-660, 2013.

[11] G. Akman, "Evaluating suppliers to include green supplier development programs via fuzzy c-means and VIKOR methods," Computers \& Industrial Engineering, vol. 86, pp. 69-82, 2015.

[12] B. Vahdani, S. M. Mousavi, H. Hashemi, M. Mousakhani, and R. Tavakkoli-Moghaddam, "A new compromise solution method for fuzzy group decision-making problems with an application to the contractor selection," Engineering Applications of Artificial Intelligence, vol. 26, no. 2, pp. 779-788, 2013.

[13] F. Mohammadi, M. K. Sadi, F. Nateghi, A. Abdullah, and M. Skitmore, "A hybrid quality function deployment and cybernetic analytic network process model for project manager selection," Journal of Civil Engineering and Management, vol. 20, no. 6, pp. 795-809, 2014.

[14] W.-H. Tsai, W. Hsu, and T. W. Lin, "New financial service development for banks in Taiwan based on customer needs and expectations," The Service Industries Journal, vol. 31, no. 2, pp. 215-236, 2011.

[15] M. K. Sayadi, M. Heydari, and K. Shahanaghi, "Extension of VIKOR method for decision making problem with interval numbers," Applied Mathematical Modelling: Simulation and Computation for Engineering and Environmental Systems, vol. 33, no. 5, pp. 2257-2262, 2009.

[16] T. Kaya and C. Kahrarnan, "Fuzzy multiple criteria forestry decision making based on an integrated VIKOR and AHP approach," Expert Systems with Applications, vol. 38, no. 6, pp. 7326-7333, 2011.
[17] M. Ashtiani and M. Abdollahi Azgomi, "Trust modeling based on a combination of fuzzy analytic hierarchy process and fuzzy VIKOR," Soft Computing, vol. 20, no. 1, pp. 399-421, 2016.

[18] H.-C. Liu, L. Liu, N. Liu, and L.-X. Mao, "Risk evaluation in failure mode and effects analysis with extended VIKOR method under fuzzy environment," Expert Systems with Applications, vol. 39, no. 17, pp. 12926-12934, 2012.

[19] Y. Ju and A. Wang, "Extension of VIKOR method for multicriteria group decision making problem with linguistic information," Applied Mathematical Modelling: Simulation and Computation for Engineering and Environmental Systems, vol. 37, no. 5, pp. 3112-3125, 2013.

[20] K. Devi, "Extension of VIKOR method in intuitionistic fuzzy environment for robot selection," Expert Systems with Applications, vol. 38, no. 11, pp. 14163-14168, 2011.

[21] S. Lu and J. Tang, "Research on evaluation of auto parts suppliers by VIKOR method based on intuitionistic language multicriteria," Key Engineering Materials, vol. 467-469, pp. 31-35, 2011.

[22] R. Roostaee, M. Izadikhah, F. H. Lotfi, and M. RostamyMalkhalifeh, "A multi-criteria intuitionistic fuzzy group decision making method for supplier selection with vikor method," International Journal of Fuzzy System Applications, vol. 2, no. 1, pp. 1-17, 2012.

[23] S.-P. Wan, Q.-Y. Wang, and J.-Y. Dong, “The extended VIKOR method for multi-attribute group decision making with triangular intuitionistic fuzzy numbers," Knowledge-Based Systems, vol. 52, pp. 65-77, 2013.

[24] J. H. Park, H. J. Cho, and Y. C. Kwun, "Extension of the VIKOR method to dynamic intuitionistic fuzzy multiple attribute decision making," Computers \& Mathematics with Applications. An International Journal, vol. 65, no. 4, pp. 731-744, 2013.

[25] J.-P. Peng, W.-C. Yeh, T.-C. Lai, and C.-P. Hsu, "Similarity-based method for multiresponse optimization problems with intuitionistic fuzzy sets," Proceedings of the Institution of Mechanical Engineers, Part B: Journal of Engineering Manufacture, vol. 227, no. 6, pp. 908-916, 2013.

[26] H. Hashemi, J. Bazargan, S. M. Mousavi, and B. Vahdani, "An extended compromise ratio model with an application to reservoir flood control operation under an interval-valued intuitionistic fuzzy environment," Applied Mathematical Modelling: Simulation and Computation for Engineering and Environmental Systems, vol. 38, no. 14, pp. 3495-3511, 2014.

[27] S. M. Mousavi, B. Vahdani, and S. Sadigh Behzadi, "Designing a model of intuitionistic fuzzy VIKOR in multi-attribute group decision-making problems," Iranian Journal of Fuzzy Systems, vol. 13, no. 1, pp. 45-65, 2016.

[28] M. Gul, E. Celik, N. Aydin, A. Taskin Gumus, and A. F. Guneri, "A state of the art literature review of VIKOR and its fuzzy extensions on applications," Applied Soft Computing, vol. 46, pp. 60-89, 2016.

[29] H. Liao and Z. Xu, "A VIKOR-based method for hesitant fuzzy multi-criteria decision making," Fuzzy Optimization and Decision Making. A Journal of Modeling and Computation Under Uncertainty, vol. 12, no. 4, pp. 373-392, 2013.

[30] Y. Li, D. L. Olson, and Z. Qin, "Similarity measures between intuitionistic fuzzy (vague) sets: a comparative analysis," Pattern Recognition Letters, vol. 28, no. 2, pp. 278-285, 2007.

[31] G. A. Papakostas, A. G. Hatzimichailidis, and V. G. Kaburlasos, "Distance and similarity measures between intuitionistic fuzzy sets: a comparative analysis from a pattern recognition point of view," Pattern Recognition Letters, vol. 34, no. 14, pp. 1609-1622, 2013. 
[32] Z. S. Xu and J. Chen, "An overview of distance and similarity measures of intuitionistic fuzzy sets," International Journal of Uncertainty, Fuzziness and Knowledge-Based Systems, vol. 16, no. 4, pp. 529-555, 2008.

[33] Z. Xu, "Intuitionistic fuzzy aggregation operators," IEEE Transactions on Fuzzy Systems, vol. 15, no. 6, pp. 1179-1187, 2007.

[34] K. T. Atanassov, "Intuitionistic fuzzy sets," Fuzzy Sets and Systems, vol. 20, no. 1, pp. 87-96, 1986.

[35] S. M. Chen and J. M. Tan, "Handling multicriteria fuzzy decision-making problems based on vague set theory," Fuzzy Sets and Systems, vol. 67, no. 2, pp. 163-172, 1994.

[36] D. H. Hong and C.-H. Choi, "Multicriteria fuzzy decisionmaking problems based on vague set theory," Fuzzy Sets and Systems, vol. 114, no. 1, pp. 103-113, 2000.

[37] Z. Xu and R. R. Yager, "Some geometric aggregation operators based on intuitionistic fuzzy sets," International Journal of General Systems, vol. 35, no. 4, pp. 417-433, 2006.

[38] E. Szmidt and J. Kacprzyk, "Entropy for intuitionistic fuzzy sets," Fuzzy Sets and Systems, vol. 118, no. 3, pp. 467-477, 2001.

[39] W. Q. Wang and X. L. Xin, "Distance measure between intuitionistic fuzzy sets," Pattern Recognition Letters, vol. 26, no. 13, pp. 2063-2069, 2005.

[40] E. Szmidt and J. Kacprzyk, "Distances between intuitionistic fuzzy sets," Fuzzy Sets and Systems, vol. 114, no. 3, pp. 505-518, 2000.

[41] P. Grzegorzewski, "Distances between intuitionistic fuzzy sets and/or interval-valued fuzzy sets based on the Hausdorff metric," Fuzzy Sets and Systems, vol. 148, no. 2, pp. 319-328, 2004.

[42] Y. Yang and F. Chiclana, "Consistency of 2D and 3D distances of intuitionistic fuzzy sets," Expert Systems with Applications, vol. 39, no. 10, pp. 8665-8670, 2012.

[43] G. Beliakov, M. Pagola, and T. Wilkin, "Vector valued similarity measures for Atanassov's intuitionistic fuzzy sets," Information Sciences, vol. 280, pp. 352-367, 2014.

[44] S.-M. Chen and C.-H. Chang, "A novel similarity measure between Atanassov's intuitionistic fuzzy sets based on transformation techniques with applications to pattern recognition," Information Sciences, vol. 291, pp. 96-114, 2015.

[45] F. E. Boran and D. Akay, "A biparametric similarity measure on intuitionistic fuzzy sets with applications to pattern recognition," Information Sciences, vol. 255, pp. 45-57, 2014.

[46] P. Intarapaiboon, "A hierarchy-based similarity measure for intuitionistic fuzzy sets," Soft Computing, vol. 20, no. 5, pp. 19091919, 2016.

[47] Y. Song, X. Wang, L. Lei, W. Quan, and W. Huang, "An evidential view of similarity measure for Atanassov's intuitionistic fuzzy sets," Journal of Intelligent \& Fuzzy Systems: Applications in Engineering and Technology, vol. 31, no. 3, pp. 1653-1668, 2016.

[48] S. Ngan, "An activation detection based similarity measure for intuitionistic fuzzy sets," Expert Systems with Applications, vol. 60, pp. 62-80, 2016.

[49] Y. Song, X. Wang, L. Lei, and A. Xue, "A novel similarity measure on intuitionistic fuzzy sets with its applications," Applied Intelligence, vol. 42, no. 2, pp. 252-261, 2015. 


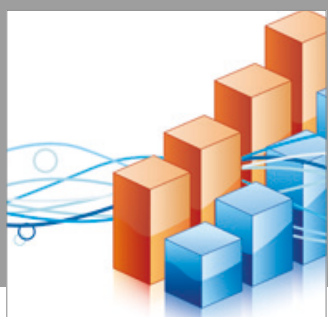

Advances in

Operations Research

vatersals

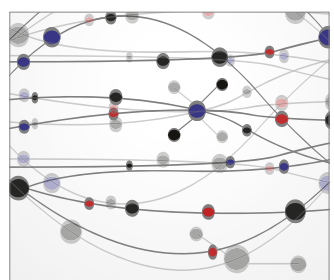

\section{The Scientific} World Journal
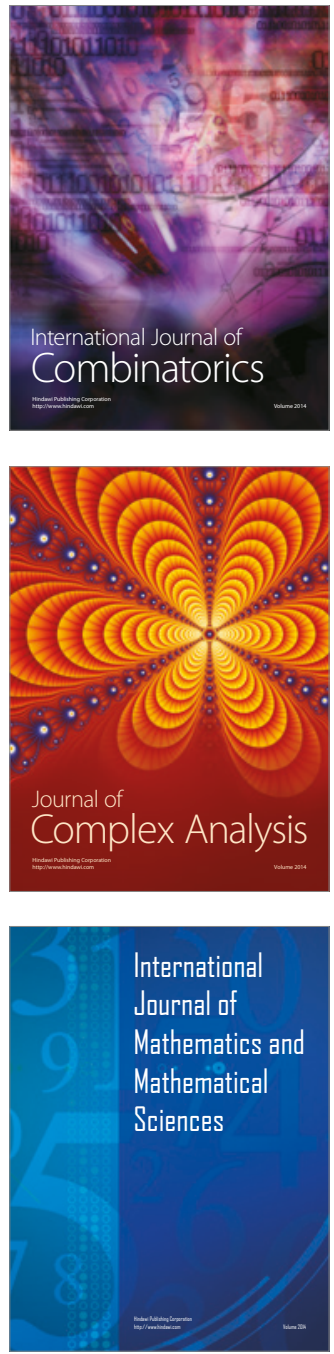
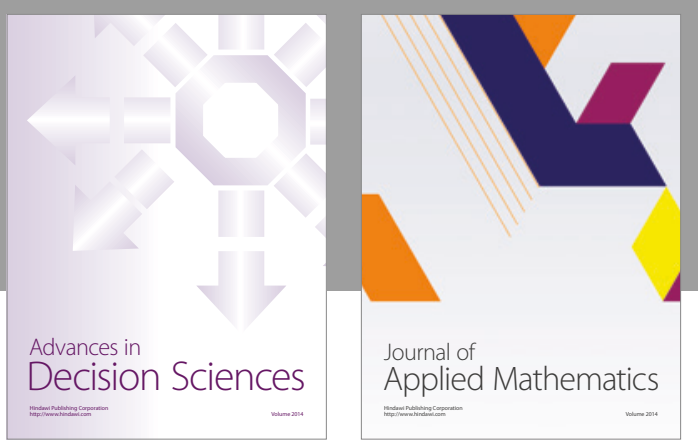

Algebra

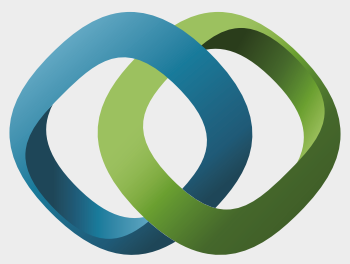

\section{Hindawi}

Submit your manuscripts at

https://www.hindawi.com
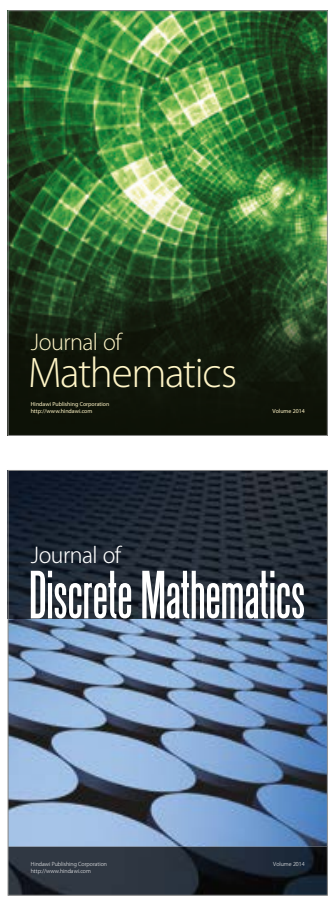

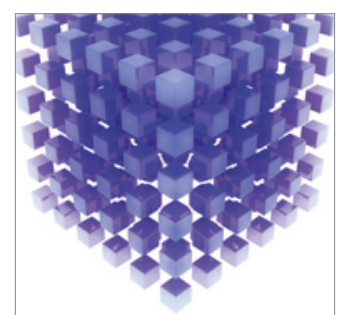

Mathematical Problems in Engineering
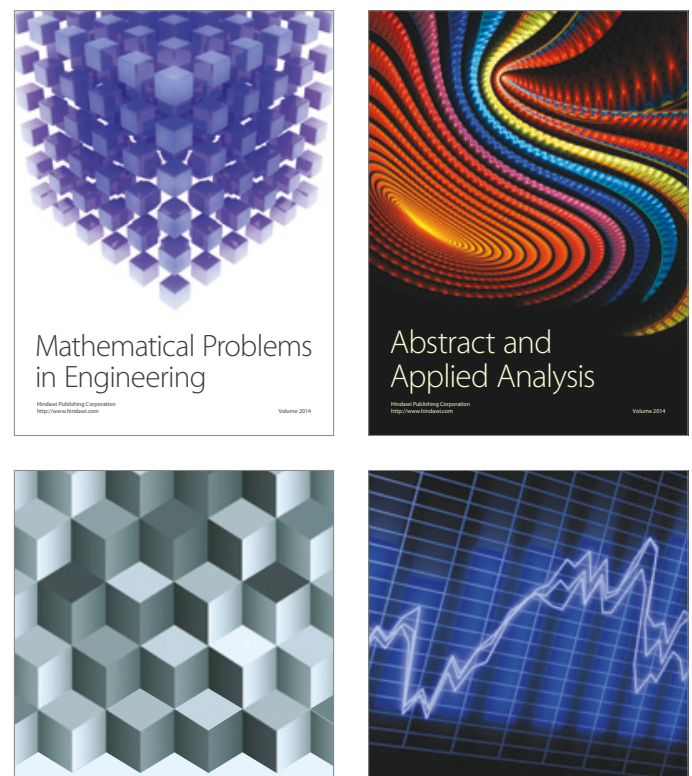

Journal of

Function Spaces

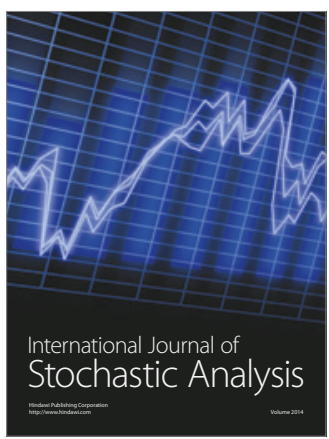

Probability and Statistics
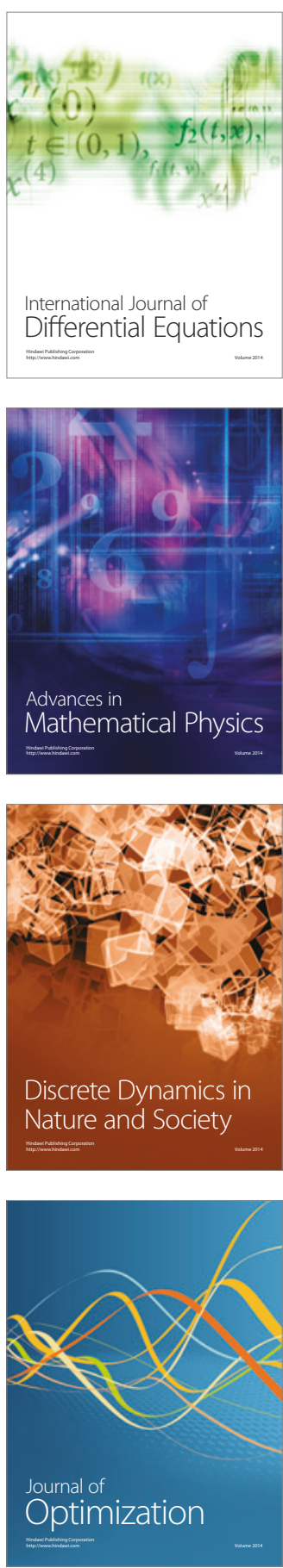